Article

\title{
The DNA Glycosylase NEIL2 Suppresses Fusobacterium-Infection-Induced Inflammation and DNA Damage in Colonic Epithelial Cells
}

\author{
Ibrahim M. Sayed ${ }^{1,2} \mathbb{}$, Anirban Chakraborty ${ }^{3}$, Amer Ali Abd El-Hafeez ${ }^{4}\left(\mathbb{D}\right.$, Aditi Sharma ${ }^{1}$, \\ Ayse Z. Sahan ${ }^{1}(\mathbb{D}$, Wendy Jia Men Huang 4 (D), Debashis Sahoo 5,6, Pradipta Ghosh 4,7,8, \\ Tapas K. Hazra ${ }^{3}$ and Soumita Das ${ }^{1, *(D)}$ \\ 1 Department of Pathology, University of California, San Diego, CA 92093, USA; \\ i4ibrahim@health.ucsd.edu (I.M.S.); a5sharma@health.ucsd.edu (A.S.); asahan@health.ucsd.edu (A.Z.S.) \\ 2 Department of Medical Microbiology and Immunology, Faculty of Medicine, Assiut University, \\ Assiut 71515, Egypt \\ 3 Department of Internal Medicine, University of Texas Medical Branch, Galveston, TX-77555, USA; \\ anibiotech1111@gmail.com (A.C.); tkhazra@utmb.edu (T.K.H.) \\ 4 Department of Cellular and Molecular Medicine, University of California, San Diego, CA 92093, USA.; \\ aam002@health.ucsd.edu (A.A.A.E.-H.); wendyjmhuang@health.ucsd.edu (W.J.M.H.); \\ prghosh@health.ucsd.edu (P.G.) \\ 5 Department of Pediatrics, University of California, San Diego, CA 92093, USA; dsahoo@health.ucsd.edu \\ 6 Department of Computer Science and Engineering, Jacob's School of Engineering, La Jolla, CA 92093, USA \\ 7 Department of Medicine, University of California, San Diego, CA 92093, USA \\ 8 Moores Cancer Center, University of California, San Diego, CA 92093, USA \\ * Correspondence: sodas@health.ucsd.edu; Tel.: +1-858-246-2062
}

Received: 4 July 2020; Accepted: 25 August 2020; Published: 28 August 2020

check for updates

\begin{abstract}
Colorectal cancer (CRC) is the third most prevalent cancer, while the majority (80-85\%) of CRCs are sporadic and are microsatellite stable (MSS), and approximately $15-20 \%$ of them display microsatellite instability (MSI). Infection and chronic inflammation are known to induce DNA damage in host tissues and can lead to oncogenic transformation of cells, but the role of DNA repair proteins in microbe-associated CRCs remains unknown. Using CRC-associated microbes such as Fusobacterium nucleatum $(F n)$ in a coculture with murine and human enteroid-derived monolayers (EDMs), here, we show that, among all the key DNA repair proteins, NEIL2, an oxidized base-specific DNA glycosylase, is significantly downregulated after $F n$ infection. Fn infection of NEIL2-null mouse-derived EDMs showed a significantly higher level of DNA damage, including double-strand breaks and inflammatory cytokines. Several CRC-associated microbes, but not the commensal bacteria, induced the accumulation of DNA damage in EDMs derived from a murine CRC model, and $F n$ had the most pronounced effect. An analysis of publicly available transcriptomic datasets showed that the downregulation of NEIL2 is often encountered in MSS compared to MSI CRCs. We conclude that the CRC-associated microbe Fn induced the downregulation of NEIL2 and consequent accumulation of DNA damage and played critical roles in the progression of CRCs.
\end{abstract}

Keywords: Fusobacterium nucleatum; inflammation; enteroid; enteroid-derived monolayer; DNA damage; base-excision repair; colorectal cancer; NEIL2; genomic instability; cancer development

\section{Introduction}

Colorectal cancer (CRC) is the third-most prevalent cancer and the fourth-most frequent cause of cancer death in the USA and around the world, according to GLOBOCAN 2018 data and the American 
Cancer Society, 2017 [1]. CRC is a multifactorial disease that is affected by genetic, epigenetic, and environmental factors, such as dietary lifestyle, physical activity, obesity, smoking, alcohol consumption, and alteration of gut microbiota [2-7]. Epigenetic alterations in CRC include aberrant DNA methylation, chromatin modifications, and noncoding microRNA expression [8]. For the genetic subtype of CRC, the presence or absence of mutations in the DNA mismatch repair system is well-documented [9]. However, this hypermutable subtype or deficient mismatch repair (dMMR) system is responsible for only $15 \%$ of CRCs, which is known as microsatellite instable (MSI) CRC [10]. The defect in the MMR pathway leads to MSI, and it is a common etiologic factor for the development of CRC, such as hereditary non-polyposis colon cancer (HNPCC), also known as Lynch syndrome [11]. The remaining $85 \%$ of the CRCs do not exhibit mutations in the mismatch repair system, and these CRCs are known as proficient mismatch repair (pMMR) or microsatellite stable (MSS) CRCs [12,13].

The persistent microbial infection triggers the induction of chronic inflammation and DNA damage and these two cellular processes, in combination, are the major risk factors for cancer development, including CRC. The alteration of gut microbes can exert a profound influence on host physiology by inducing a chronic inflammatory state, which affects stem cell precursors and the production of toxic metabolites leading to the development of CRC [14,15]. Numerous bacterial species, such as Bacteroides fragilis, Helicobacter pylori, Escherichia coli, Enterococcus faecalis, Clostridium septicum and Fusobacterium nucleatum play roles in the pathogenesis of CRC [16,17]. Fusobacterium nucleatum (Fn) is a pathogenic anaerobic gram-negative gut microbe that is also associated with CRC cases $[18,19] . F n$ is associated with more than $50 \%$ of CRCs, including MSI and MSS cancers, with a higher prevalence in the proximal colon than distal colon [20-22]. Moreover, high levels of $F n$ in CRC patients' tissues was associated with poor patient outcome and recurrence of infection in post-chemotherapy [23]. Several possible mechanisms have been proposed, such as binding of the FadA adhesin of $F n$ to E-cadherin leading to activation of Wnt/ $\beta$-catenin signaling, which then causes overexpression of Wnt genes, oncogenes c-Myc, Cyclin D1, and inflammatory genes involved in CRC progression [19,24]. Fn selectively promotes the growth of cancerous cells by inducing $\mathrm{Wnt} / \beta$-catenin modulator Annexin A1 [25]. A recent study showed that $F n$ caused DNA damage and promoted cell proliferation by the Ku70/p53 pathway in oral cancer cells [26].

Pathogenic bacteria induce the release of reactive oxygen and nitrogen species (RONS), which eventually can lead to mutagenic oxidized DNA base lesions [27]. Host cells respond to DNA damage by initiating DNA damage response (DDR) following infection. Failure of DDR can lead to the accumulation of mutations, inducing genome instability, and oncogene activation resulting in cancer $[28,29]$. However, to date, there is no report on how colon cancer-associated bacteria such as $F n$ infection can impact DNA damage and inflammation and how the BER proteins play a critical role in the etiology of colorectal cancer. ROS-induced oxidative DNA base lesions are predominantly repaired via the highly conserved base excision repair (BER) pathway, which is initiated by DNA glycosylases. [30]. Among the five oxidized base-specific DNA glycosylases, OGG1 and NTH1 remove oxidized purines and pyrimidines, respectively, from duplex DNA. E. coli Nei-like (NEIL1-3) proteins are a distinct family of DNA glycosylases that remove both oxidized purines and pyrimidines. They initiate the excision of lesions present in a single-stranded region, a replication fork, or transcription bubble mimic [31-36]. The reduced expression of NEIL1, NEIL2, and elevated expression of NEIL3 is involved in the progression of several types of cancer as a consequence of somatic mutation load [37]. The decreased level or loss of activity of NEIL2 and, to a lesser extent, NEIL1, is a risk factor for the progression of cancers such as lung cancer and squamous cell carcinoma in the oral cavity [38-41], and poor survival in patients with estrogen-receptor-positive breast cancer [42]. BER is the major pathway for the repair of such DNA lesions, and thereby a robust DNA damage response through BER can reduce the risk of colon carcinogenesis [43]. Recently, we have shown that Helicobacter pylori infection leads to degradation of NEIL2 and subsequent accumulation of oxidative DNA damage, a plausible cause of gastric cancer [44]. This result is in agreement with our earlier studies showing that 
the Neil2-null mice are highly sensitive to inflammatory stress and also accumulate oxidized DNA bases in their genome [31].

Here, we determined the effect of $F n$ infection on the host DNA repair pathways and analyzed the expression level of vital proteins using stem cell-based enteroid-derived monolayers (EDMs). Among the DNA repair proteins, MSH2/MSH6 (involved in the MMR pathway) and Ku 70 (involved in nonhomologous end joining (NHEJ)) were upregulated, and only NEIL2 (BER) was downregulated following infection. Fn infection increased the inflammatory cytokines and induced DNA damage in colonic EDMs. Consequently, $F n$ infection leads to double-strand DNA breaks, which were more prominent when the BER protein (NEIL2) was depleted. This study demonstrated that $F n$ infection exerted a differential effect on DNA repair pathways in colonic EDMs. It further provided novel insight into the critical role of NEIL2 in controlling DNA damage accumulation and inflammation following $F n$ infection and, thus, established a plausible link between impaired DNA repair, uncontrolled inflammation, and CRC progression.

\section{Materials and Methods}

All experiments involving human and animal subjects were performed following the relevant guidelines and regulations of the University of California, San Diego, CA, USA and the National Institutes of Health (NIH).

\subsection{Animals}

The Neil2 knockout (KO) C57BL/6 mice were generated and characterized as previously described [32]. The breeding and maintenance of these mice were carried out as per the approved guidelines of the Animal Care and Ethics Committee of UTMB, Galveston, TX, USA (Hazra protocol 0606029D). APC ${ }^{\mathrm{Min} /+}$ (Adenomatous polyposis coli) mice were bred, maintained, and subsequently used for multiple experiments following the University of California San Diego Institutional Animal Care and Use Committee (IACUC) policies (Protocol \#S18086).

\subsection{Bacterial Cultures}

Fusobacterium nucleatum (Fn) (ATCC-25586) was obtained from ATCC. Fn was cultured anaerobically at $37^{\circ} \mathrm{C}$ for $48 \mathrm{~h}$ in the chopped cooked meat media (Anaerobic Systems, Morgan Hill, CA, USA) inside an anaerobic chamber containing an anaerobic gas kit generating system (MGC, AnaeroPACK System, New York, NY, USA). Colon enteroid-derived monolayer (EDM) was infected with $(F n)$ at a multiplicity of infection (moi) of 100 for $24 \mathrm{~h}$. Escherichia coli K12 strain DH10B (ATCC-PTA5105) was cultured on Luria Broth (LB) agar and LB broth and used to infect EDM at a moi of 100 for $24 \mathrm{~h}$. Adherent-invasive Escherichia coli strain LF82 (AIEC-LF82), isolated from the specimens of Crohn's disease patients, was obtained from Arlette Darfeuille-Michaud (Clermont-Ferrand, France) and was cultured as previously described [45]. EDM was infected with LF82 at a moi of 100 for $24 \mathrm{~h}$. H. pylori strain (ATCC-26695) was incubated with the Brucella broth supplemented with $10 \%$ fetal bovine serum (FBS) in a shaker at $37^{\circ} \mathrm{C}$ in $10 \% \mathrm{CO}_{2}$. Colon EDMs were infected with $\mathrm{H}$. pylori at moi 100 for $24 \mathrm{~h}$.

\subsection{Isolation and Maintenance of Colonic Organoids}

Colon organoids were isolated from the colonic tissue specimens of wild-type (WT) C57BL/6 mice, Neil2 KO mice, $C P C-A P C^{\mathrm{Min} /+}$ mice, healthy human subjects, and colorectal cancer (CRC) patients, as described previously [45-49]. Briefly, colon tissues were digested by collagenase type I ( $2 \mathrm{mg} / \mathrm{mL}$; Life Technologies Corporation, Grand Island NY, USA) containing gentamicin $(50 \mu \mathrm{g} / \mathrm{mL}$, Life Technologies Corporation). The digested tissues were incubated at $37^{\circ} \mathrm{C}$ for $30-40 \mathrm{~min}$ cycles with intervals of $10 \mathrm{~min}$ each. The tissue specimens were subjected to vigorous pipetting between successive incubations and were constantly monitored to confirm the dislodgement of the intestinal crypts from the tissues. After the separation of $80 \%$ of the colon crypts, the collagenase was inactivated with media (DMEM/F12 with HEPES, 10\% fetal bovine serum (FBS) (Sigma-Aldrich, MO, USA), and the colon crypts were filtered 
using a 70- $\mu \mathrm{m}$ cell strainer. The number of live cells was measured in a hemocytometer following staining by trypan blue (Sigma-Aldrich). The cells were suspended in the basement membrane matrix (matrigel) (Corning Inc., Kennebunk, ME, USA) supplemented with 50\% stem cell-enriched conditioned medium (CM) with WNT 3a, R-spondin, and Noggin. Y27632 (ROCK inhibitor, $10 \mu \mathrm{M}$ ) and SB431542 (an inhibitor for TGF- $\beta$ type I receptor, $10 \mu \mathrm{M}$ ) were added to the media to support the growth of organoids. For the human enteroids, media and supplements were obtained from the HUMANOID CoRE (UC San Diego, CA, USA), as reported previously [45].

\subsection{The Preparation of Enteroid-Derived Monolayers (EDMs)}

EDMs were prepared from colonic enteroids as previously described [45,50]. Briefly, the enteroids were trypsinized, and the isolated cells were filtered, counted, resuspended in $5 \% \mathrm{CM}$, and $2 \times 10^{5}$ cells (per well) were plated in 0.4- $\mu \mathrm{m}$ polyester membrane Transwell (Corning, Cat \#3470, MO, USA) precoated with matrigel (1:40 dilution). The cells were then allowed to differentiate for 48-72 h. Transepithelial electrical resistance (TEER) and Lgr5 were used as markers for the quality and differentiation of EDMs $[45,47]$. Differentiated EDMs were challenged with different microbes, as described earlier. The supernatant was collected from the basolateral part of the Transwell for cytokine analysis, and the cells were lysed for RNA extraction to check for the expression of target genes by qPCR.

For murine colonic organoids, we used 3 age and gender-matched mice in each group, and for human colonic organoids, we used biopsy specimens from 3 adult healthy human subjects. Each organoid line isolated from one mouse or from one human subject was biobanked and differentiated to EDM. Therefore, each EDM was derived from one mouse, and there were three different cultures from WT mice and three different cultures from NEIL2 KO mice used in this study. Additionally, there were 3 different human organoid and EDM cultures used in this study.

\subsection{RNA Isolation and qPCR for Gene Expression Analysis}

RNA was extracted from uninfected EDMs, and EDMs infected with Fn, E. coli K12-, and LF82 using Quick-RNA MicroPrep Kit (Zymo Research, Irvine, CA, USA) according to the manufacturer's instructions. cDNA was synthesized using the qScript ${ }^{\mathrm{TM}} \mathrm{CDNA}$ SuperMix (Quantabio, Beverly, MA, USA). Quantitative PCR (qPCR) was carried out using $2 \times$ SYBR Green qPCR Master Mix (Biomake, Houston, TX, USA) for target genes, and the data was normalized to the housekeeping 18s rRNA gene using the $\Delta \Delta \mathrm{Ct}$ method. Primers were designed using the National Center for Biotechnology Information (NCBI) Primer Blast software (https://www.ncbi.nlm.nih.gov/tools/primer-blast/index.cgi) and the Roche Universal Probe Library Assay Design software https://ifescience.roche.com/en_us/ brands/universal-probe-library.html\#assay-design-center (Table 1).

Table 1. Sequences of the primers used in the study. IL: interleukin.

\begin{tabular}{|c|c|c|c|}
\hline Gene & Species & Forward Primer $\left(5^{\prime} \rightarrow 3^{\prime}\right)$ & Reverse Primer $\left(5^{\prime} \rightarrow 3^{\prime}\right)$ \\
\hline 18srRNA & & GTAACCCGTTGAACCCCATT & CCATCCAATCGGTAGTAGCG \\
\hline NEIL1 & mouse & TCGTAGACATCCGTCGCTTT & TGTCTGATAGGTTCCGAAGTACG \\
\hline NEIL2 & mouse & CTGCCGCCTTTCAGTCTCT & TCTGGATCAAACCGAAGGAA \\
\hline NTH1 & mouse & GCATGAACTCAGGGAAGGAAGA & CCTCACCATTAGCCGCTTCA \\
\hline OGG1 & mouse & TTATCATGGCTTCCCAAACC & GTACCCCAGGCCCAACTT \\
\hline NEIL1 & human & CCAGGCAGTGGGAAGTCA & AGGGAGGGTGGCAGAGTC \\
\hline NEIL2 & human & GGGGCAGCAGTAAGAAGCTA & GGAATAATTTCTTTCCATGGACCT \\
\hline NTH1 & human & GACAGCATCCTGCAGACAGA & TTGATGTATTTCACCTTGCTCCT \\
\hline OGG1 & human & CCAGACCAACAAGGAACTGG & CAAATGCATTGCCAAGGA \\
\hline IL-8/KC & mouse & CGCTTCTCTGTGCAGCGCTGCTGCT & AAGCCTCGCGACCATTCTTGAGTC \\
\hline IL-8 & Human & GAGCACTCCATAAGGCACAAA & ATGGTTCCTTCCGGTGGT \\
\hline MLH1 & Human & GATTACCCCTTCTGATTGACA & ACTGAGGCTTTCAAAACA \\
\hline MLH3 & Human & CGCACGAGCCTCAAGATCC & TCTGACTGGAAATAATTGCCTGGA \\
\hline MSH2 & Human & CAGTATATTGGAGAATCGCA & AGGGCATTTGTTTCACC \\
\hline MSH6 & Human & GСTTCTTCСССAAGTCTCCG & AGAAGTCACAACTGGTGGGG \\
\hline PMS2 & Human & ACTGAGTCTAAGCACTGCGG & TGACATCGCTCAGTGCACAA \\
\hline Ku70 & Human & CCACAGGAAGAAGAGTTGGA & CTGCTCTGGAGTTGCCATGA \\
\hline
\end{tabular}




\subsection{Proteome Profiler Array}

To assess the cytokine levels following $F n$ infection, a proteome profiler array (human cytokine array; R \& D Systems, Minneapolis, MN, USA) was used according to the manufacturer's instructions. Briefly, the capture antibody of cytokines and chemokines were spotted on nitrocellulose membranes precoated with 40 cytokines. The samples/secondary antibody mixture was added to the immobilized capture antibodies on the membrane following the manufacturer's protocols. After washing, the streptavidin-horseradish peroxidase and chemiluminescent reagents were added to the membrane. The detected signal was proportional to the amount of cytokine bound. Quantification of specific cytokines was performed using ELISA.

\subsection{The Measurement of Interlekin (IL)-8 Cytokine by ELISA}

Supernatants were collected from WT, NEIL2 KO EDMs, and APC ${ }^{\mathrm{Min} /+}$ polyp either uninfected or infected with Fn. IL-8 (KC) was measured using the mouse CXCL1/KC DuoSet ELISA kit (R \& D Systems) according to the manufacturer's instructions. The level of IL-8 was compared between Fn-infected EDMs vs. the uninfected EDMs from WT, Neil2 KO mice, and APC ${ }^{\mathrm{Min} /+}$ polyp.

\subsection{Immunoblot for Detection of Base Excision Repair and Cellular Signaling Proteins}

Whole-cell lysates were prepared using the RIPA buffer (50-mM Tris (pH 7.4), 150-mM NaCl, $1 \%$ NP-40, 0.25\% Na-deoxycholate, and 1-mM EDTA with protease inhibitor cocktail (Sigma, MO, USA) from uninfected and Fn-infected WT and NEIL2 KO EDMs and subsequently tested for the expression levels of BER proteins. The proteins in the whole-cell extracts from EDMs were separated onto a Bio-Rad 4-20\% gradient Bis-Tris Gel, then electrotransferred on nitrocellulose $(0.45-\mu \mathrm{m}$ pore size; GE Healthcare, Chicago, IL, USA) membrane using 1X Bio-Rad transfer buffer. The membranes were blocked with 5\% w/v skimmed milk in TBST buffer (1X Tris-buffered Saline and $0.1 \%$ Tween 20), then immunoblotted with appropriate antibodies (NEIL2, NTH1, and OGG1; all anti-rabbit; and in-house antibodies used in 1:500 dilutions). Glyceraldehyde 3-phosphate dehydrogenase (GAPDH) and histone deacetylase 2 (HDAC2) (GeneTex, Irvine, CA, USA) were used as loading controls. The membranes were extensively washed with $1 \%$ TBST, followed by incubation with anti-isotype secondary antibody (GE Healthcare) conjugated with horseradish peroxidase in 5\% skimmed milk at room temperature. Subsequently, the membranes were further washed three times (10 min each) in 1\% TBST and developed using ECL ${ }^{\text {TM }}$ Western Blotting Detection Reagents (RPN2209, GE Healthcare) and imaged immediately. For the detection of phosphorylated Ataxia telangiectasia-mutated kinase (pATM) and total ATM, cell lysates were separated on 8\% SDS-PAGE and transferred to Polyvinylidine Fluride (PVDF) membranes (Millipore, Billerica, MA, USA). Membranes were blocked with phosphate buffered saline (PBS) supplemented with $5 \%$ nonfat milk or bovine serum albumin and then incubated sequentially with primary and secondary antibodies. The dilution of the primary antibodies was as follows: anti-p-ATM, 1:1000; anti-ATM, 1-1000; and anti-tubulin, 1-1000 (used as a loading control). All the Western blot images were quantified using ImageJ automated digitizing system based on three independent gel images $(n=3)$.

\subsection{Assessment of $\gamma H 2 A X$ Phosphorylation by Immunofluorescence (IF)}

Either uninfected or Fn-infected EDMs from WT and Neil2 KO mice were fixed with $4 \%$ paraformaldehyde (PFA) at room temperature for $15 \mathrm{~min}$, washed once with $1 \mathrm{X}$ phosphate-buffered saline, permeabilized, and blocked with IF buffer (0.1\% Triton TX-100 and 2-mg/mL bovine serum albumin (BSA) in PBS) for $1 \mathrm{~h}$. Samples were then incubated with anti-p- $\gamma \mathrm{H} 2 \mathrm{AX}$ (Santa Cruz biotechnology, Inc. Santa Cruz, CA, USA 1:500). Incubation with the primary antibody was performed at $4{ }^{\circ} \mathrm{C}$ overnight. After three consecutive washes with PBS (10 min each), the EDMs were incubated with secondary antibodies at a dilution of 1:500 for $60 \mathrm{~min}$ at room temperature in the dark. Washes were performed as before, and the membranes were dried and mounted in gel/mount antifade aqueous 
mounting medium (Biotium, Fremont, CA, USA with coverslips. Images were acquired using a Leica CTR4000 Confocal Microscope with a 63X objective. Z-stack images were obtained by imaging approximately $4-\mu \mathrm{m}$-thick sections of cells in all channels. After capturing the image, the fluorescence intensity of $\gamma \mathrm{H} 2 \mathrm{AX}$ staining/cell was calculated using ImageJ.

\subsection{Analysis of Accumulation of DNA Strand Break by Long Amplicon Quantitative PCR (LAqPCR)}

Genomic DNA (gDNA) was extracted from WT, NEIL2-KO, and APC ${ }^{\mathrm{Min} /+}$ EDMs, either uninfected or infected with $F n$, using a Gentra Puregene Cell Kit (Qiagen, Hilden, Germany) following the manufacturer's instructions. Accumulation of DNA strand-break was assessed in both transcribed genes (polß and globin) following the protocol described previously [31,44]. Briefly, the extracted gDNA was quantified by Pico Green (Molecular Probes, ThermoFischer, Waltham, MA, USA). The gene-specific DNA strand-break accumulation was measured by long amplicon quantitative-PCR (LA-qPCR) by amplifying a $6.5-\mathrm{kb}$ region of pol $\beta$ and the $8.7-\mathrm{kb}$ region of globin genes, according to the following conditions: $94{ }^{\circ} \mathrm{C}$ for $30 \mathrm{~s}\left(94^{\circ} \mathrm{C}\right.$ for $30 \mathrm{~s}, 55-60{ }^{\circ} \mathrm{C}$ for $30 \mathrm{~s}$ depending on the oligo annealing temperature, and $65^{\circ} \mathrm{C}$ for $10 \mathrm{~min}$ ) for $25 \mathrm{cycles}$ and $65^{\circ} \mathrm{C}$ for $10 \mathrm{~min}$. In principle, strand break (SB) following the excision of the oxidized DNA base by DNA glycosylases or DNA double-strand breaks, in general, will cause stalling of the Taq DNA polymerase, since they may not be able to bypass the strand break site. Thus, a decreased level of the long amplicon PCR product would reflect a higher level of DNA SBs. A small DNA fragment for each gene was also amplified to normalize the amplification of large fragments. Amplification of a smaller fragment should be similar for the samples because of a lower probability of SB formation in a shorter fragment. Thus, amplification of the short fragment is used for normalization of the differential amplification of the long fragment. The amplified products were visualized on agarose gels and quantified using the ImageJ automated digitizing system (NIH) based on at least two independent replicates. The extent of damage was calculated in terms of the relative band intensity with WT untreated subjects considered as 100 . The oligo sequences used in the study are listed in Table 2.

Table 2. The oligo sequences used in the study.

\begin{tabular}{|c|c|c|c|}
\hline Primer Name & Gene Name & Sequences & PCR \\
\hline m-Pol $\beta$-LA-F & Pol $\beta$ (mouse) & TAT СТС ТСТ TCС ТСT TCA СТT СТC CCC TGG & LA-qPCR \\
\hline $\mathrm{m}$-Pol $\beta$-LA-R & Pol $\beta$ (mouse) & CGT GAT GCC GCC GTT GAG GGT CTC CTG & LA-qPCR \\
\hline $\mathrm{m}-\beta$ Globin-LA-F & $\beta$ globin (mouse) & TTG AGA CTG TGA TTG GCA ATG CCT & LA-qPCR \\
\hline m- $\beta$ Globin-LA-R & $\beta$ globin (mouse) & CCT TTA ATG CCC ATC CCG GAC T & LA-qPCR \\
\hline m-Polß-SA-F & Polß (mouse) & TATGGACCCCCATGAGGAACA & SA-PCR \\
\hline m-Polß-SA-R & Pol $\beta$ (mouse) & AACCGTCGGCTAAAGACGTG & SA-PCR \\
\hline $\mathrm{m}-\beta$ Globin-SA-F & $\beta$ globin (mouse) & ACACTACTCAGAGTGAGACCCA & SA-PCR \\
\hline $\mathrm{m}-\beta$ Globin-SA-R & $\beta$ Globin (mouse) & ATACCCAATGCTGGCTCCTG & SA-PCR \\
\hline
\end{tabular}

\subsection{Measurement of Oxidative DNA/RNA Damage}

The level of damaged bases was quantified using the DNA/RNA Oxidative Damage ELISA Kit (Cayman Chemical, Ann Arbor, Michigan, USA, Clone 7E6.9) according to the manufacturer's instructions and previous reports [51,52]. Briefly, this assay is an ELISA immunoassay that detects oxidized the guanine species 8-hydroxy-2'-deoxaguanosine from DNA and 8-hydroxyguanine from either DNA or RNA. Briefly, this assay is based on a competition between oxidatively damaged guanosine species and 8-hydroxy deoxaguanosine acetylcholinesterase conjugate (DNA/RNA oxidative damage tracer) for a limited amount of DNA/RNA Oxidative Damage Monoclonal antibody. The amount of tracer, which is held constant, that will bind to the monoclonal antibody is inversely proportional to the concentration of oxidatively damaged guanine species in the well. The secondary antibody (goat polyclonal anti-mouse IgG) has been previously attached to the well and will react with the antibody oxidatively damaged guanine complex. The reaction is developed by the addition of 
Ellman's reagent that has substrated to acetylcholinesterase. The intensity of the color is determined spectrophotometrically at wavelengths $405-420$ and is proportional to the amount of oxidative damage tracer bound to the well, which is inversely proportional to the amount of free 8-hydroxy guanosine present in the well. Standard curves were developed using standards provided in the kits, and the standards were diluted in the same culture media of the infection experiment to confirm that the matrix of the standards and the samples is the same. We used this assay to compare the level of oxidatively damaged bases in WT and NEIL2 KO colon EDMs either uninfected or Fn-infected. Additionally, we used this technique to assess the level of DNA/RNA damage generated after infection with several bacteria (E. coli K12, AIEC LF-82, H. pylori, and E. coli NC101).

\subsection{Lactate Dehydrogenase (LDH) Assay}

Supernatants collected from WT and NEIL2 KO colonic EDMs (either uninfected or Fn-infected) were assayed for LDH using a LDHGlo ${ }^{\mathrm{TM}}$ Cytotoxicity Assay kit (Promega, Madison, WI, USA) according to the manufacturer's instructions, as described previously [45]. Briefly, supernatants were diluted in LDH storage buffer, and then, an equal volume of LDH detection reagent was added to the diluted sample. The LDH activity was determined by measurement of the degree of luminescence. LDH-positive control (purified lactate dehydrogenase from rabbit muscle) was included in each assay. Serial dilutions from the $\mathrm{LDH}$-positive control $(32-0.5 \mathrm{mU} / \mathrm{mL})$ were done and included in this assay. Culture media was used to determine the medium background.

\subsection{Analysis of Datasets with the CRC Patients}

Publicly available CRC datasets GSE13067, GSE13294, GSE26682, and GSE18088 were downloaded from the National Center for Biotechnology Information (NCBI) Gene Expression Omnibus website (GEO) (PMID: 11752295, 15608262, and 23193258) and renormalized using RMA (robust multichip average) (PMID: 12582260, and 12925520). MSI/MSS status was manually annotated by going through GEO descriptions. Boxplots of NEIL2, NEIL1, OGG1, NTHL1, APEX1, POLB, and LIG3 expression values were computed using Hegemon (hierarchical exploration of gene expression microarrays online) analysis framework (PMID: 22308455, 22081019, and 26789870). Hegemon is a web-based analysis tool for the visualization and analysis of gene expression datasets. Boxplots were computed for individual cohorts, as well as combined cohorts. Significance of differential expression is computed using both t-tests and ANOVA with R statistical software (R version 3.6.1; http://www.r-project.org/).

\subsection{Statistics}

Results are expressed as mean \pm SEM. $p$-value was determined by GraphPad Prism software 6 (GraphPad Software, La Jolla, CA, USA) using the unpaired student's $t$-test. $p<0.05$ was considered significant.

\section{Results}

\subsection{NEIL2 is Downregulated in the Human Colonic EDMs Following Fn Infection}

To assess the expression levels of BER enzymes (Figure 1A), we infected colonic EDMs with Fusobacterium nucleatum $(F n)$ as a model pathogenic bacteria that are associated with CRC $[18,19]$. It was found that $F n$ infection significantly downregulated NEIL2 transcript level, while the NTH1 transcript level was upregulated, and the transcript levels of NEIL1 and OGG1 remained unaltered (Figure 1B). Since the mismatch repair (MMR) is involved in MSI CRCs, we thus examined the transcript levels of key components involved in MMR [53,54]. The levels of MLH1 and MLH3 remain unchanged after $\mathrm{F} n$ infection, whereas the levels of MSH2 and MSH6 were increased, and PMS2 was downregulated following Fn infection (Figure 1C). Since Fn infection caused a decrease in the Ku70 level (a classical nonhomologous end joining (NHEJ) marker) in oral cancer cells [26], we tested its level as well in colon EDM and found that the upregulation of the Ku70 occurred following Fn 
infection (Figure 1D). These results thus demonstrate that $F n$ infection specifically suppressed the DNA glycosylase NEIL2, compared to all other repair proteins tested that are involved in various repair pathways. To demonstrate the specificity of the Fn-mediated downregulation of NEIL2, human colonic EDMs were infected with the commensal E. coli-K12 strain (Figure 1E) or IBD (Inflammatory bowel disease) -associated adherent invasive E. coli (E. coli LF82 isolated from IBD patients) (Figure 1F). The transcript level of NEIL2 was not affected following infection with these bacteria (Figure 1E,F), indicating the downregulation of NEIL2 following Fn infection is specific.

A

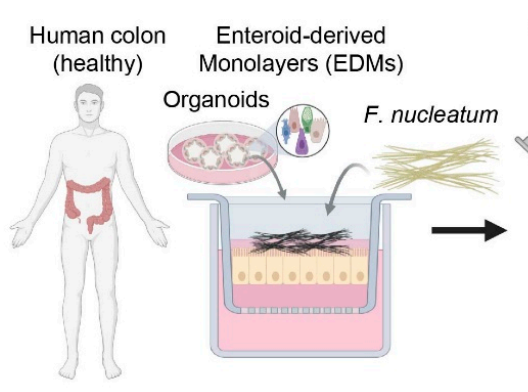

The expression of repair proteins

qRT-PCR

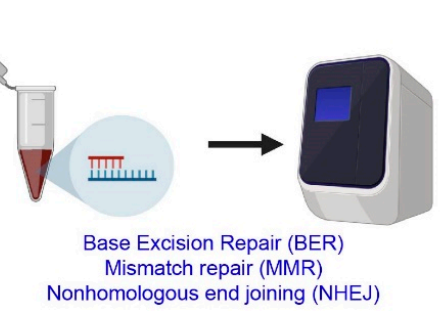

B

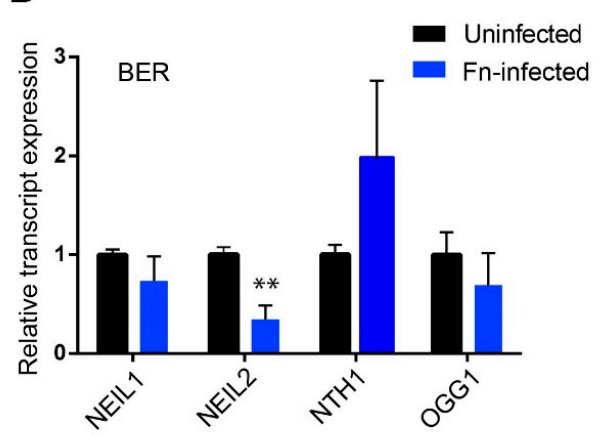

C

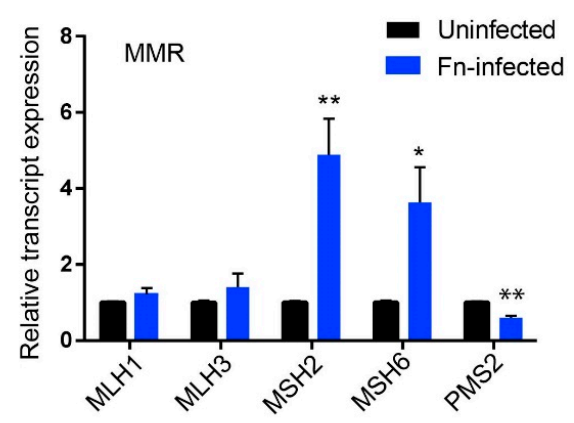

D

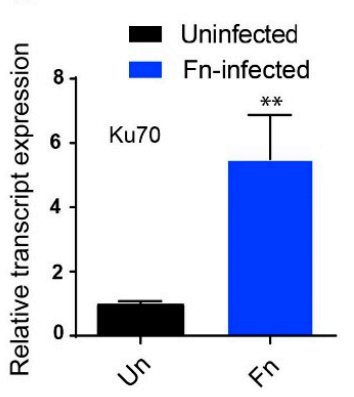

E

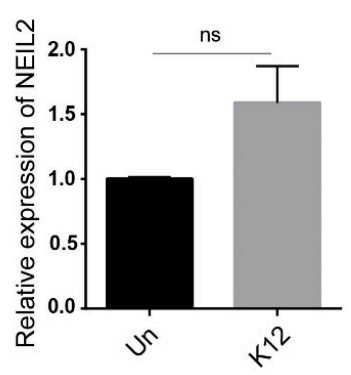

F

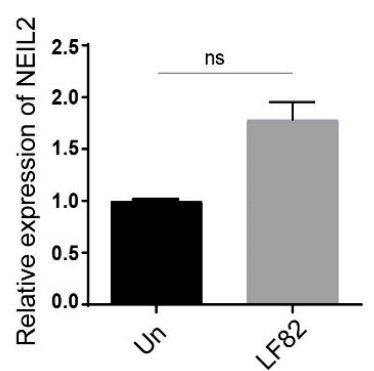

Figure 1. The specific downregulation of NEIL2 in human colonic EDMs following Fusobacterium nucleatum (Fn) infection. (A-D) Human colonic EDMs (from 3 healthy subjects) were infected with $F n$ at moi 100 for $24 \mathrm{~h}$. (A) Schematic representation of the experimental design. The relative levels of BER transcripts NEIL1, NEIL2, NTH1, and OGG1 (B); MMR transcripts MLH1, MLH3, MSH2, MSH6, and PMS2 (C); and NHEJ marker Ku70 transcript (D) were determined by qRT-PCR. (E,F) Human colonic EDMs were infected with commensal Escherichia coli-K12 strain (E) or pathogenic IBD-associated adherent invasive E. coli LF-82 (F) to determine the expression level of NEIL2 following Fn infection. In (B-F), the expression level of the transcripts was normalized to the housekeeping gene (18srRNA), and the normalized expression value was compared with the respective uninfected control cells. Data represent the mean \pm SEM of three separate experiments. ${ }^{*}$ indicates $p \leq 0.05$, and ${ }^{* *}$ indicates $p \leq 0.01$, as calculated by the unpaired two-tailed student's $t$-test. ns: not significant. 


\subsection{Fn Infection Suppressed the Expression of NEIL2 in the Murine Colonic EDMs}

To determine the effect of $F n$ infection on the expression of BER proteins, we infected murine colonic EDMs with $F n$ and then measured the expression of DNA glycosylases at the transcript and protein levels (Figure 2A). Similar to human EDMs, Fn infection led to the downregulation of NEIL2 and NEIL1 transcripts. In contrast, OGG1 and NTH1 transcript levels were either unchanged or upregulated, respectively, probably as a compensatory host mechanism due to $F n$ infection (Figure 2B). Next, we assessed the expression level of BER proteins in the EDM cell lysates and found that Fn infection suppressed the expression of the NEIL2 protein. In contrast, the expression of NTH1 was upregulated significantly (Figure 2C-E).

A

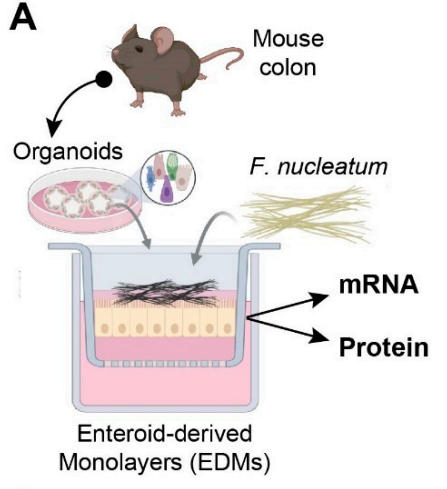

C

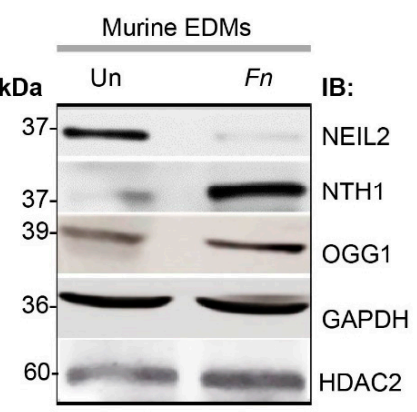

B

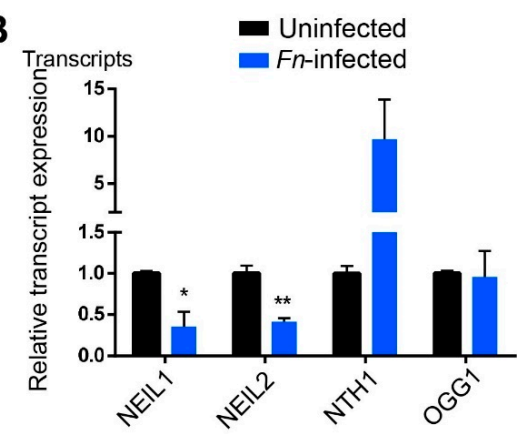

D

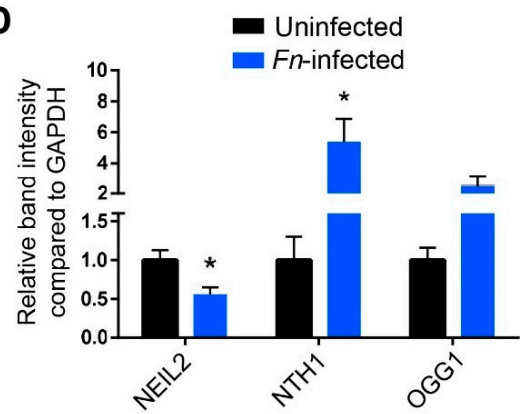

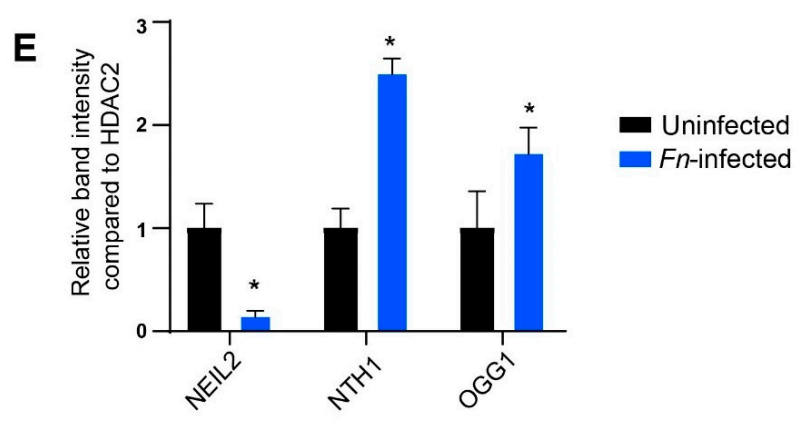

Figure 2. The downregulation of NEIL2 in murine colonic EDMs following $F n$ infection. (A) Schematic representation of the experimental design. (B) qRT-PCR to detect the expression levels of the BER enzymes following $F n$ infection of wild-type (WT) murine colonic EDMs for $24 \mathrm{~h}$. The expression level of the transcripts was normalized to the 18srRNA and compared with the corresponding uninfected level. Data represent the mean \pm SEM of three independent experiments. * and ${ }^{* *}$ indicate $p<0.05$ and $p \leq 0.01$, respectively (C) Immunoblot to check the levels of NEIL2, NTH1, and OGG1 proteins in the whole-cell extract of uninfected and $F n$-infected EDMs. GAPDH and HDAC2 (histone deacetylase 2 ) were used as loading controls. Three independent experiments $(n=3)$ were performed, and one representative figure is shown. Data represent the mean band density \pm SEM. (D,E) The relative band intensity was normalized to both GAPDH (D) and HDAC2 (E) and compared between $F n$-infected and uninfected, which was set as unity $(n=1) .{ }^{*}$ indicate $p<0.05$. 


\subsection{The Role of NEIL2 in Controlling Inflammation and DNA Strand-Break Accumulation Following Fn Infection in Colonic EDMs}

To determine whether $F n$ infection can induce inflammatory cytokines, we collected supernatants from colonic EDMs, either mock-infected or infected with $\mathrm{Fn}$. By analyzing the proteome profile array, we found that IL-8 and its homolog, CXCL1, were the major cytokines induced and secreted by Fn-infected EDMs (Figure 3A). The effect of NEIL2 on the expression of proinflammatory cytokines was further assessed using the WT vs. Neil2 KO mouse EDMs following infection with $F n$. It was found that $F n$ infection upregulated KC (IL-8) transcripts in both the EDMs; however, NEIL2 KO EDMs had a four-fold higher KC compared to the WT EDMs following Fn infection (Figure 3B). Similarly, ELISA analyses also revealed that Neil2 KO EDMs have a significantly higher KC expression compared to the WT EDMs following Fn infection (Figure 3C). As we have shown that NEIL2 prevents DNA damage accumulation following infection with $\mathrm{H}$. pylori [44], we therefore examined the level of oxidized DNA bases in WT vs. Neil2 KO EDMs. Fn infection indeed led to the accumulation of oxidized DNA base lesions, and Fn-infected Neil2 KO EDMs accumulated a relatively higher level of oxidized DNA base lesions compared to Fn WT EDMs (Figure 3D). Furthermore, the level of DNA strand break was assessed using LA-qPCR in representative Pol $\beta$ and $\beta$-globin genes in the genomic DNA extracted from colonic EDMs from WT and Neil2 KO mice after the challenge with $F n$. We indeed observed a significantly higher level of DNA strand-break accumulation in both the Pol $\beta$ and $\beta$-globin genes in Neil2 KO EDMs compared to WT EDMs following Fn infection (Figure 3E).

\subsection{NEIL2 Knockdown Exacerbated Fn-Induced DNA Double-Strand Breaks (DSBs)}

Since $F n$ infection increased DNA strand breaks, we next investigated the formation of $\gamma \mathrm{H} 2 \mathrm{AX}$ foci, a marker of DSBs, by confocal microscopy and found that $F n$ infection induced the formation of $\gamma \mathrm{H} 2 \mathrm{AX}$ foci (Figure 4A). We then assessed the possible link between NEIL2 deficiency and DSB accumulation following $F n$ infection and found a significantly higher number of $\gamma \mathrm{H} 2 \mathrm{AX}$ foci in Neil2 KO EDMs compared to WT EDMs (Figure 4A). The intensity of $\gamma \mathrm{H} 2 \mathrm{AX} /$ cell was calculated. As seen in Figure 4B, there is no difference in the intensity between WT and in Neil2 KO EDMs in the baseline level (without infection). The intensity of $\gamma \mathrm{H} 2 \mathrm{AX}$ was increased after $F n$ infection, and a significantly higher intensity was recorded in Neil2 KO EDMs compared to WT following Fn infection (Figure 4B).

Next, we assessed the effect of $F n$ infection on the activation of Ataxia telangiectasia-mutated kinase (ATM) protein by Western analysis. ATM is a serine/threonine kinase that regulates cell cycle checkpoints and DNA repair. ATM is activated by autophosphorylation (pATM) on Ser1981 in response to DSBs. We indeed found that $F n$ infection increased the expression of the pATM protein, and the ratio of pATM/total ATM was significantly higher in Fn-infected EDMs than the corresponding uninfected EDMs. Additionally, the expression of PATM was significantly higher in Fn-infected NEIL2 KO EDMs compared to Fn-infected WT EDMs (Figure 4C), indicating DNA DSB accumulation in NEIL2-deficient cells.

To investigate the fate of $F n$-infected EDMs and the degree of cell death, we measured the level of LDH in the culture media. We monitored the level of cell death using supernatants collected from WT and NEIL2 KO EDMs infected or not with Fn. Following Fn infection, cell death was increased, which was significantly higher in NEIL2 KO EDM compared to WT EDMs (Figure 4D). 
A
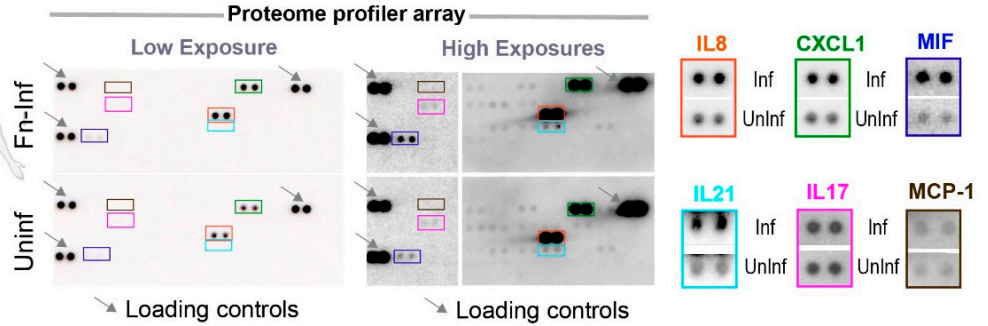

B

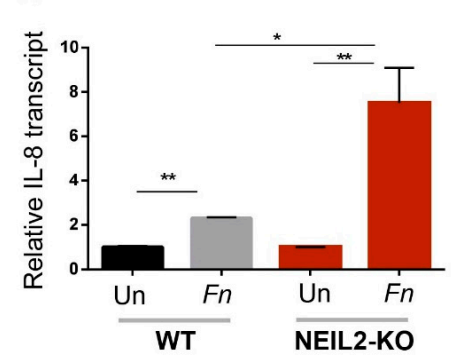

D

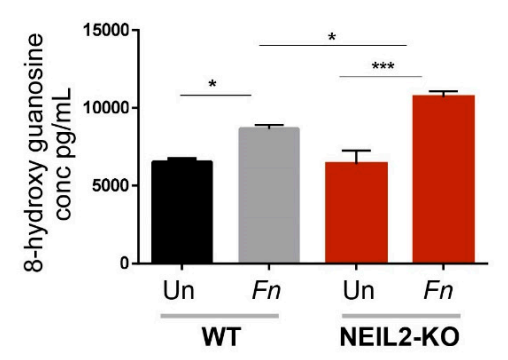

E (ii)

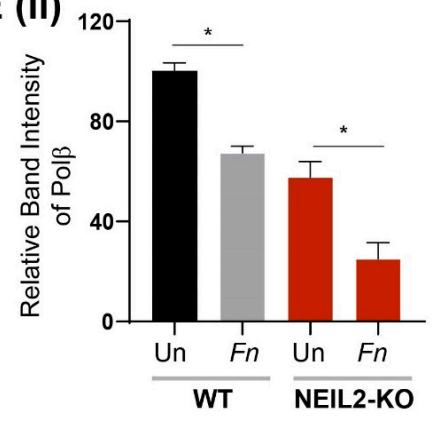

C
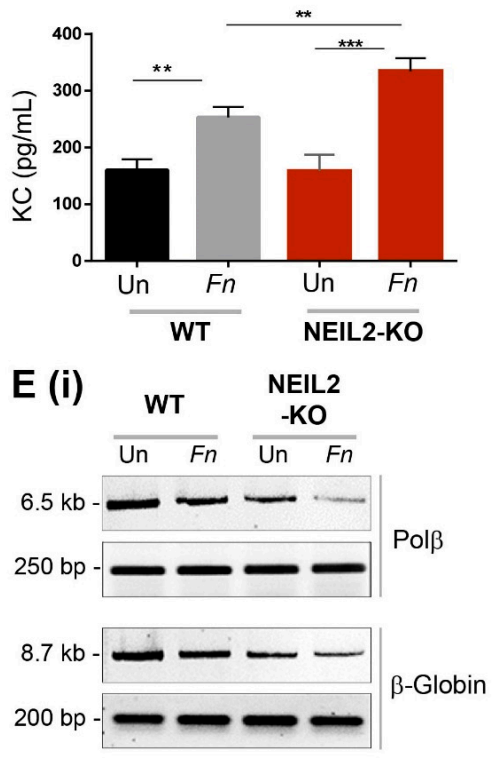

E (iii)

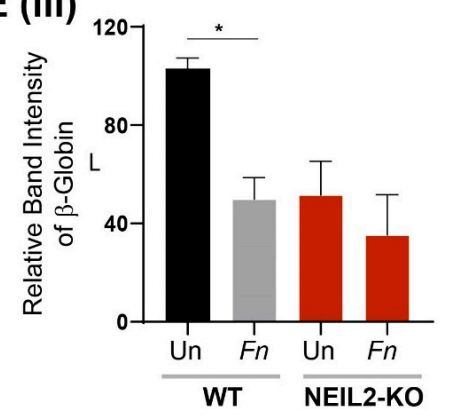

Figure 3. NEIL2 is crucial for limiting the inflammation and DNA damage induced by $F n$ infection. (A) Supernatants from uninfected and $F n$-infected EDMs were analyzed for cytokines by proteome profiler arrays. Both low (left) and high (right) exposures were presented. Interleukin (IL)-8 and its homolog, CXCL1, were the major cytokines that were significantly upregulated in response to $F n$ infection, as shown in the boxes. (B) The differential expression of IL-8/Cxcl-1 was determined by qRT-PCR in WT and Neil2 knockout (KO) EDMs either untreated or infected with $F n$. (C) The level of Cxcl-1/KC cytokine was measured in the supernatants from the EDMs of WT or Neil2 KO mice either uninfected (Un) or infected with $F n$ by ELISA. (D) The supernatants of WT and Neil2 KO EDMs, either uninfected (Un) or infected with $F n$, were analyzed for oxidative DNA/RNA damage. (E) (i) WT and Neil2 KO EDMs were either uninfected or infected with $F n$, then harvested for genomic DNA isolation. Long amplicon quantitative-PCR (LA-qPCR) was performed to evaluate the level of DNA strand-break accumulation following $F n$ infection. Representative gels show the amplification of each long fragment ( 7-8 kB) (upper panel) normalized to that of a short fragment ( $250 \mathrm{bp})$ (lower panel) of the corresponding ( $\mathrm{Pol} \beta$ and $\beta$-Globin) genes. The relative band intensity of $\mathrm{Pol} \beta$ (ii) and $\beta$-Globin (iii) was calculated. Data was generated from the mean \pm SEM of three independent experiments, where ${ }^{*} p<0.05,{ }^{* *} p<0.01$, and ${ }^{* * *} p<0.001$. 
A

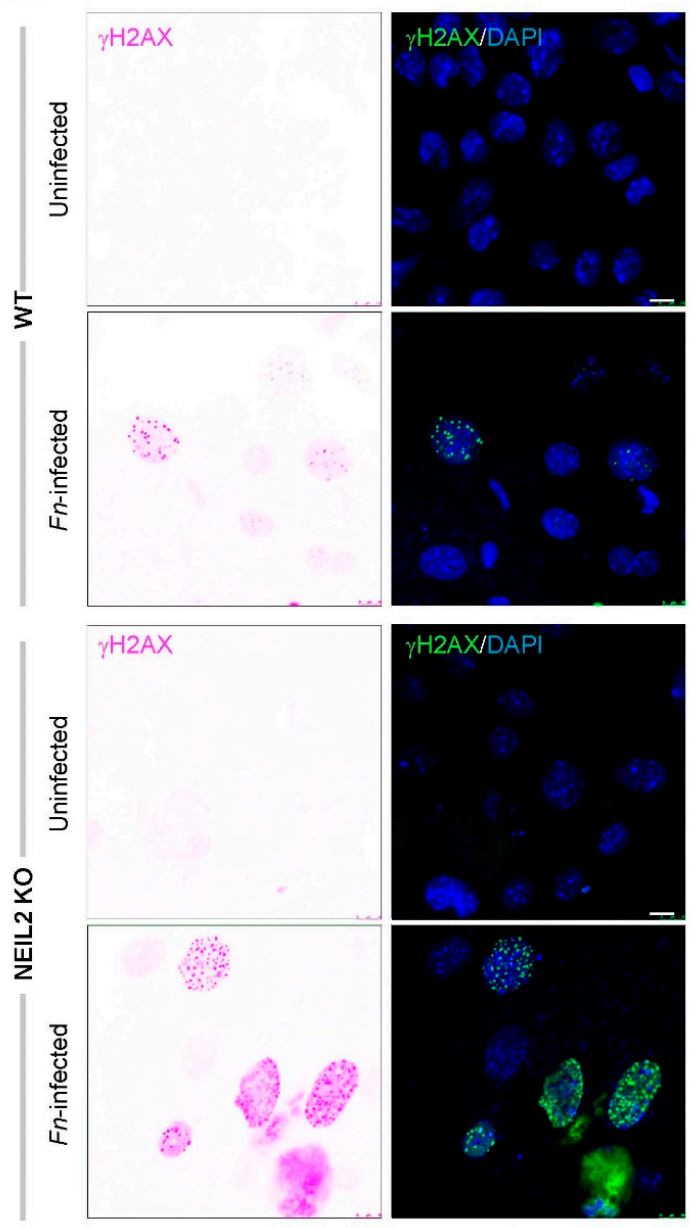

D

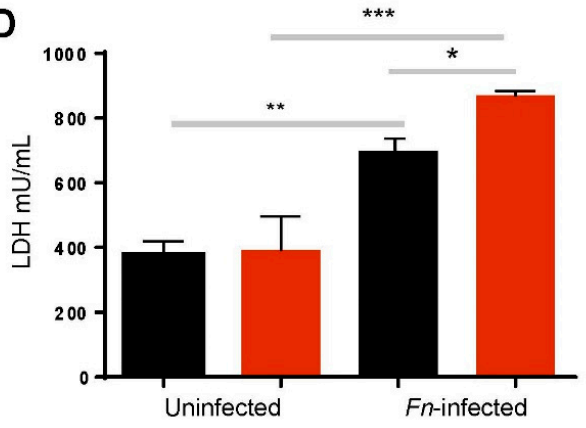

B

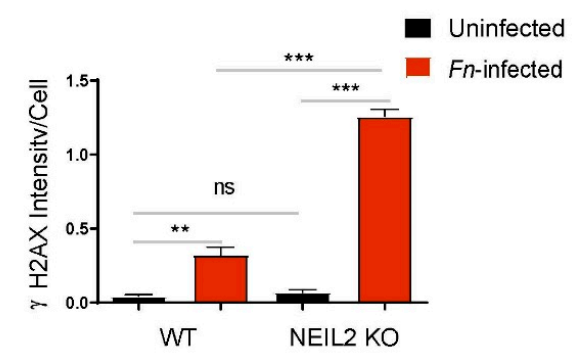

C
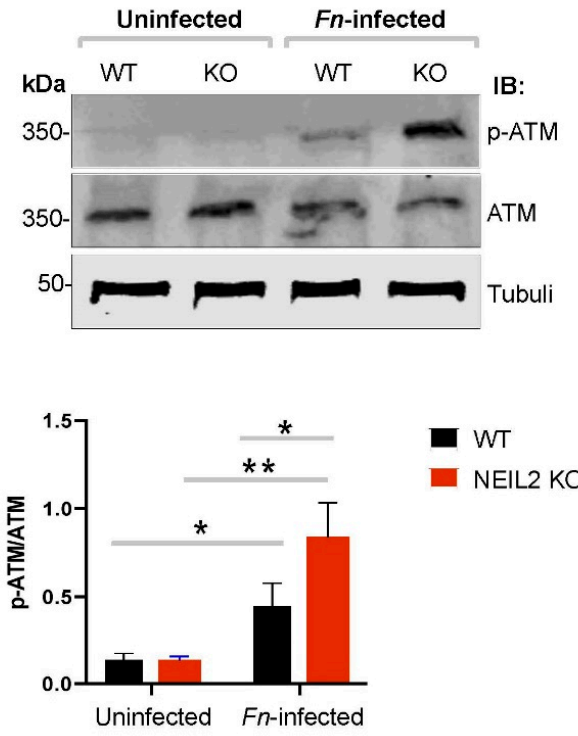

- WT

- NEIL2 KO a

- NEIL2 KO

Figure 4. NEIL2 knockdown exacerbated Fn-induced DNA double-strand breaks (DSBs). (A) The level of $\gamma \mathrm{H} 2 \mathrm{AX}$ (a marker of DSBs, green) was determined by immunofluorescence (IF); DAPI was used for nuclei staining (blue). WT and NEIL2 KO colonic EDMs either uninfected or infected with $F n$ were used to measure the amount of DSBs. (B) Using ImageJ, the intensity of $\gamma \mathrm{H} 2 \mathrm{AX}$ in each cell was calculated from all the four conditions shown in (A) and plotted. (C) The levels of phosphorylated Ataxia telangiectasia-mutated kinase (pATM) and total ATM was determined in whole cell lysates of both EDMs. Tubulin was used as a loading control (upper panel). The relative expression level of pATM normalized with those of total ATM were quantified by the ImageJ software. The expression level of pATM/ATM was compared in Fn-infected EDMs vs. uninfected EDMs and Fn-NEIL2 KO EDMs vs. Fn-WT EDMs (lower panel). (D) LDH assay was performed on supernatants collected from WT and NEIL-2 KO EDMs either uninfected or infected with $F n$. Data was generated from the mean \pm SEM of three independent experiments. ${ }^{*}$ indicates $p<0.05,{ }^{* *} p<0.01$, and ${ }^{* * *} p<0.001$. 


\subsection{Fn Infection Downregulated NEIL2 and Increased Oxidative Damage in the Murine CRC Model}

To understand the effect of $F n$ infection on the expression of BER proteins in CRC, we analyzed their expression in CDX2 Cre APC ${ }^{\mathrm{Min} /+}$ mice as the most commonly used murine CRC model. These mice developed multiple intestinal neoplasia and died within 8-12 weeks and were used to simulate human familial adenomatous polyposis (FAP) [55]. Additionally, Fn infection can increase the colon tumorgenesis in these mice in vivo [19]. The enteroids were isolated from the uninvolved region (normal, no polyp) and the involved/affected regions (polyps) of the colonic specimens of CDX2 Cre $\mathrm{APC}^{\mathrm{Min} /+}$ mice. Similar to our previous observation in humans and WT murine EDMs, Fn infection suppressed the transcriptions of NEIL1 and NEIL2. In contrast, the transcriptions of NTH1 and OGG1 were either upregulated or unchanged in EDMs generated from uninvolved and involved regions (Figure 5A,B). Fn increased the inflammatory response in APC ${ }^{\mathrm{Min} /+}$ polyp EDMs, as shown by the increase in KC/IL-8 expression by qRT-PCR and further confirmed by ELISA (Figure 5C,D). Next, we assessed the DNA strand-break levels in the Pol $\beta$ and $\beta$-globin genes from APC ${ }^{\mathrm{Min} /+}$ EDMs either untreated or infected with $F n$ using LA-qPCR (Figure 5E). We observed a significantly higher level of DNA strand-break accumulation in both the Pol $\beta$ and $\beta$-globin genes following $F n$ infection compared to uninfected EDMs (Figure 5E).

To determine the impact of $F n$ infection on oxidative damage generated in APC ${ }^{\mathrm{Min} /+}$ EDMs, we measured the level of oxidatively damaged bases in the supernatants of APC ${ }^{\mathrm{Min} /+}$ EDMs infected with $F n$ and compared with commensal E. coli $\mathrm{K} 12$ and other gut pathogens associated with CRC or IBD (Figure 6A). A significantly higher level of oxidative DNA base damages was produced by colon cancer-producing bacteria such as E. coli NC101 strain, H. pylori, and Fn (Figure 6A) than by commensal and other gut pathogens. When comparing the level of oxidized base adducts produced from different colon cancer pathogens to untreated EDMs, we found that $F n$ infection had the highest oxidative DNA damage levels, followed by H. pylori and E. coli NC101 (Figure 6B). Collectively, these results showed that $F n$ could suppress the expression of BER proteins NEIL2 in the murine CRC model, leading to an increase in the inflammatory response and an accumulation of DNA strand breaks, which could eventually contribute to the development of CRC.

\subsection{NEIL2 Is Downregulated in the MSS-CRCs Patients}

CRC is classified into two categories: (i) the microsatellite instability-high (MSI-H) group, which has defects in the DNA mismatch repair (MMR) system and accounts for $15 \%$ of tumors, and (ii) the microsatellite stable (MSS) group, with proficient MMR proteins, which accounts for the remaining $85 \%$ of tumors [56-58]. Previously, a set of gastric cancer patients with and without microsatellite instability (named MSI and MSS, respectively) showed a differential expression profile of some of the DNA repair genes [59]. Here, we have examined the expression of several key BER proteins in MSI vs. MSS CRCs in four different publicly available datasets with GSE13067, GSE13294, GSE26682, and GSE18088 [60-64]. Interestingly, the analysis of the samples from the MSI vs. MSS group revealed that the level of NEIL2 (Figure 7A-E), but not other BER proteins (NEIL1, OGG1, NTHL1, APEX1, Polb, and LigIII; Figure 7F-K), is significantly decreased in the MSS group compared to the MSI group. Collectively, these results indicate the role of NEIL2 in MSS-CRCs, where mismatch repair proteins are efficient. 
A

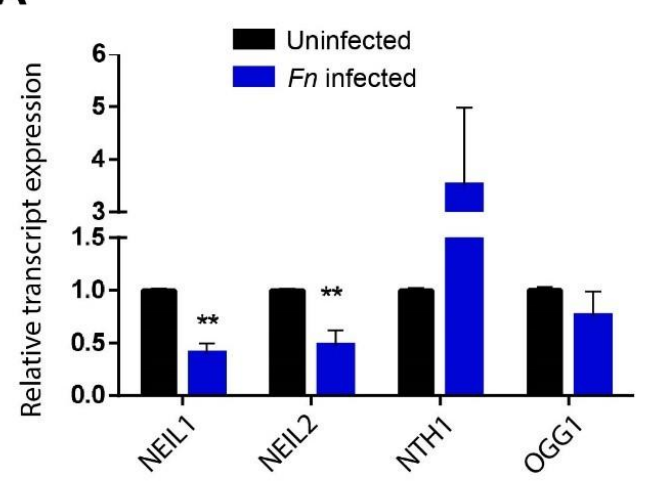

C

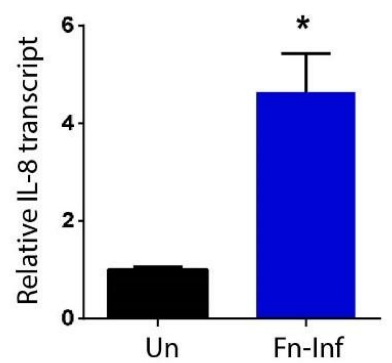

D

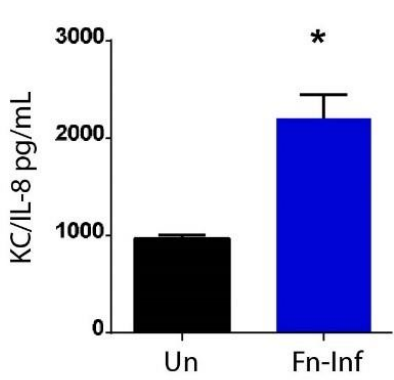

B

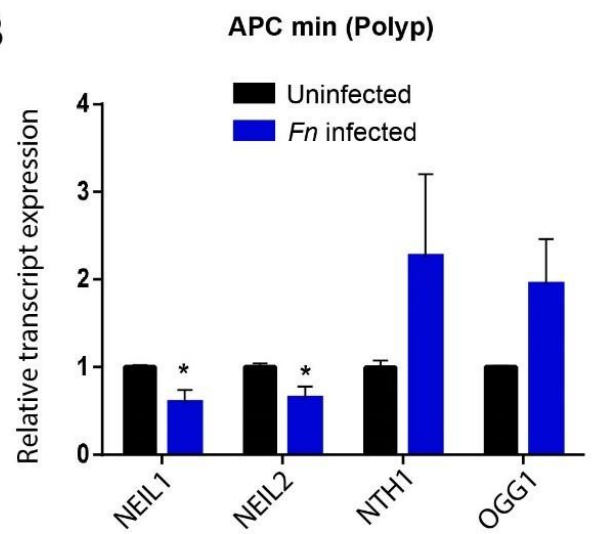

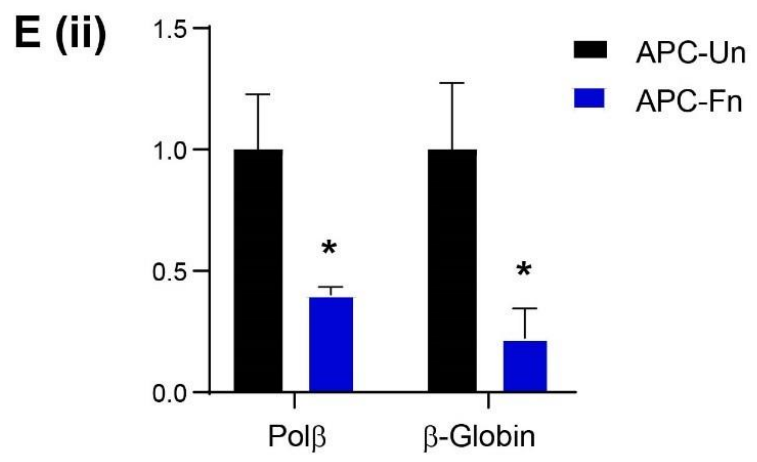

Figure 5. Fn-infection downregulated the NEIL2 transcript and increased the oxidative DNA damage in the murine colorectal cancer (CRC) model. (A) APC Min/+ EDMs derived from the uninvolved region of the colon were infected with $F n$ for $24 \mathrm{~h}$, as previously described in the Methodology section; then, the level of BER transcripts (NEIL1, NEIL2, NTH1, and OGG1) was determined by qRT-PCR. Data represent the mean \pm SEM of four separate experiments. ${ }^{* *}$ indicates $p \leq 0.001$. (B) APC ${ }^{\mathrm{Min} /+}$ EDMs derived from the polyp region of the colon were infected with Fn; then, the level of BER transcripts (NEIL1, NEIL2, NTH1, and OGG1) was determined by qRT-PCR. Data represent the mean \pm SEM of three separate experiments. * indicates $p \leq 0.05$. (C) $\mathrm{APC}^{\mathrm{Min} /+}$ EDMs derived from the polyp region of the colon were infected with $F n$; then, the transcript and expression levels of KC/IL-8 were determined by qRT-PCR (D) The level of Cxcl-1/KC cytokine was measured in the supernatants from the EDMs of APC ${ }^{\mathrm{Min} /+}$ EDMs derived from the polyp region either uninfected (Un) or infected with $F n$ by ELISA. (E) (i) LA-qPCR was performed to evaluate the level of DNA strand breaks after Fn-infection in $\mathrm{APC}^{\mathrm{Min} /+}$ EDMs. The representative gels show the amplification of each long fragment $(\sim 7-8 \mathrm{kB})$ (upper panel) normalized to that of a short fragment ( $250 \mathrm{bp}$ ) (lower panel) of the corresponding (Pol $\beta$ and $\beta$-Globin) genes. (ii) The relative band intensity of Pol $\beta$ and $\beta$-Globin was calculated. Data was generated from the mean \pm SEM of three independent experiments where ${ }^{*} p<0.05$. 
A

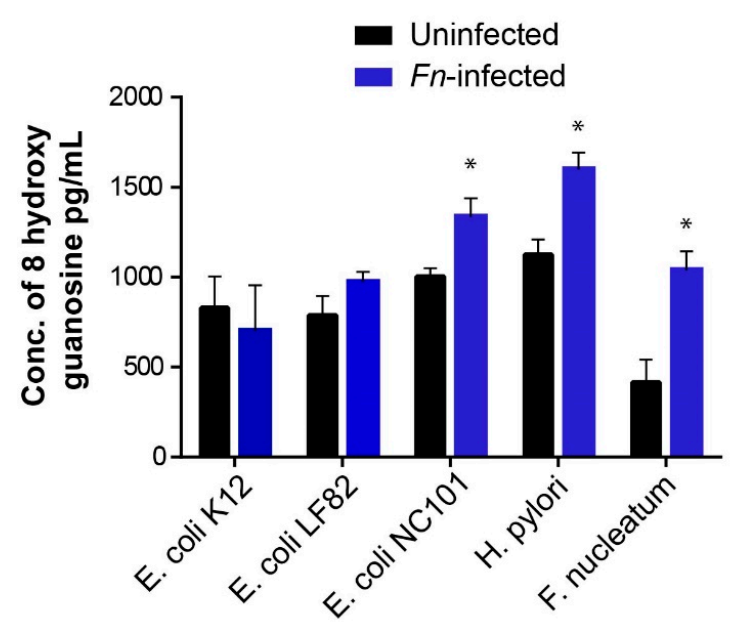

B

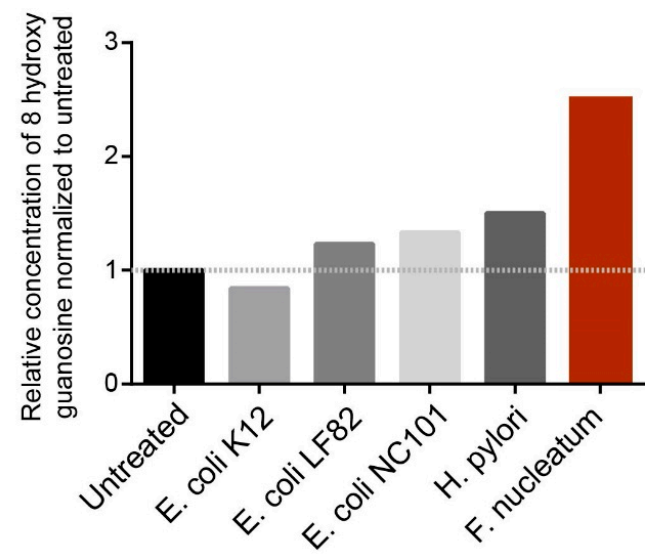

Figure 6. Fn-infection was the highest inducer of the oxidative DNA/RNA damage in the murine CRC model. (A) $\mathrm{APC}^{\mathrm{Min} /+}$ EDMs derived from the uninvolved region of the colon were infected with different microbes: commensal E. coli K12; IBD-associated adherent-invasive E. coli LF82; and colon cancer-associated pathogens (NC101, H. pylori, and Fn). The infection with all the previous microbes was done for $24 \mathrm{~h}$, and the supernatants were collected from the uninfected and infected EDMs from the same experiments and assessed for oxidative DNA damage (right). Data represent the mean \pm SEM of three separate experiments. ${ }^{*}$ indicates $p \leq 0.05$. (B) The relative level of the oxidized bases generated by each microbe was normalized to the level of the oxidized bases in uninfected cells, which was arbitrarily set as 1 , and the level of the oxidized bases in the infected EDMs was calculated. The relative production of the oxidized base was compared among different microbes, as indicated. 
A

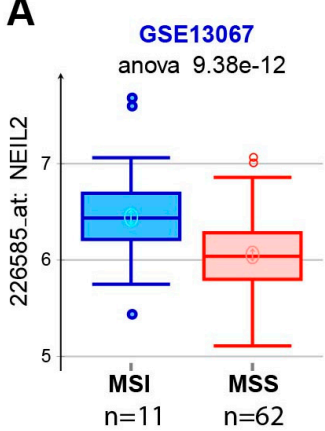

E GSE Combined

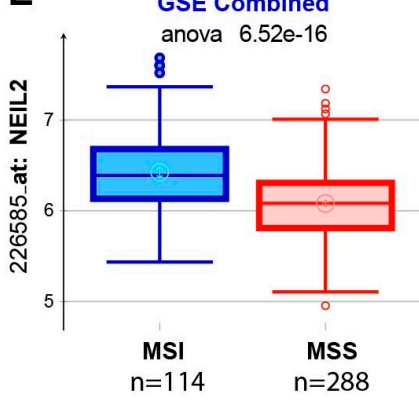

G

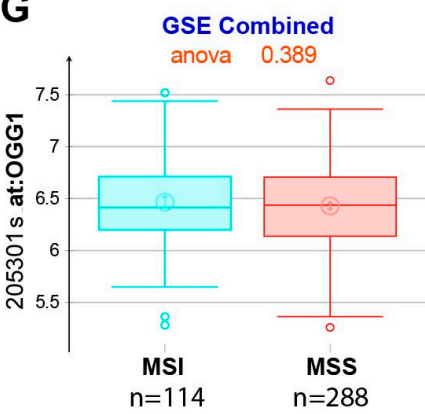

$J$

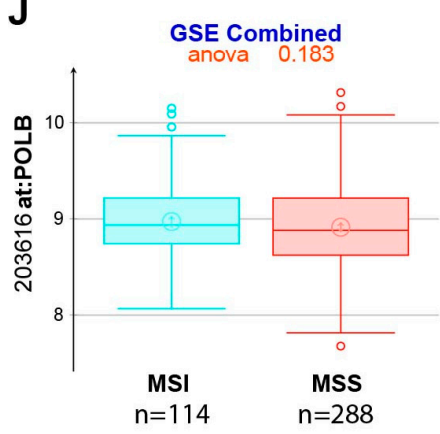

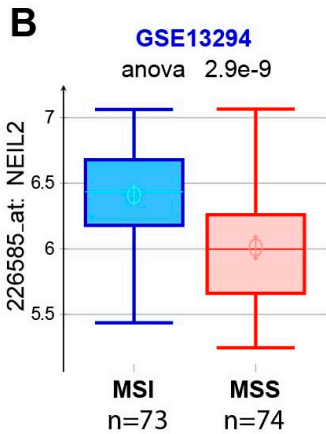
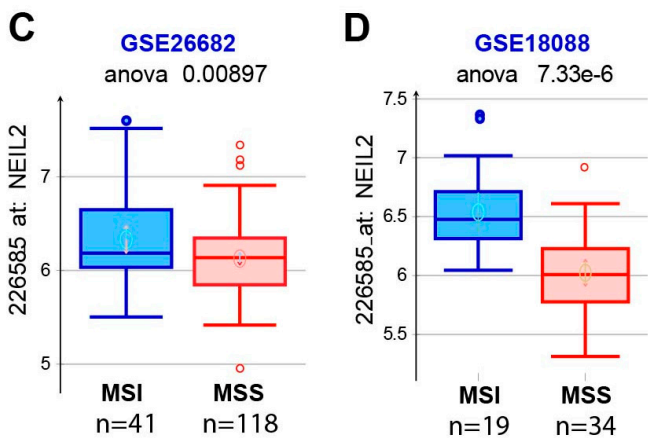
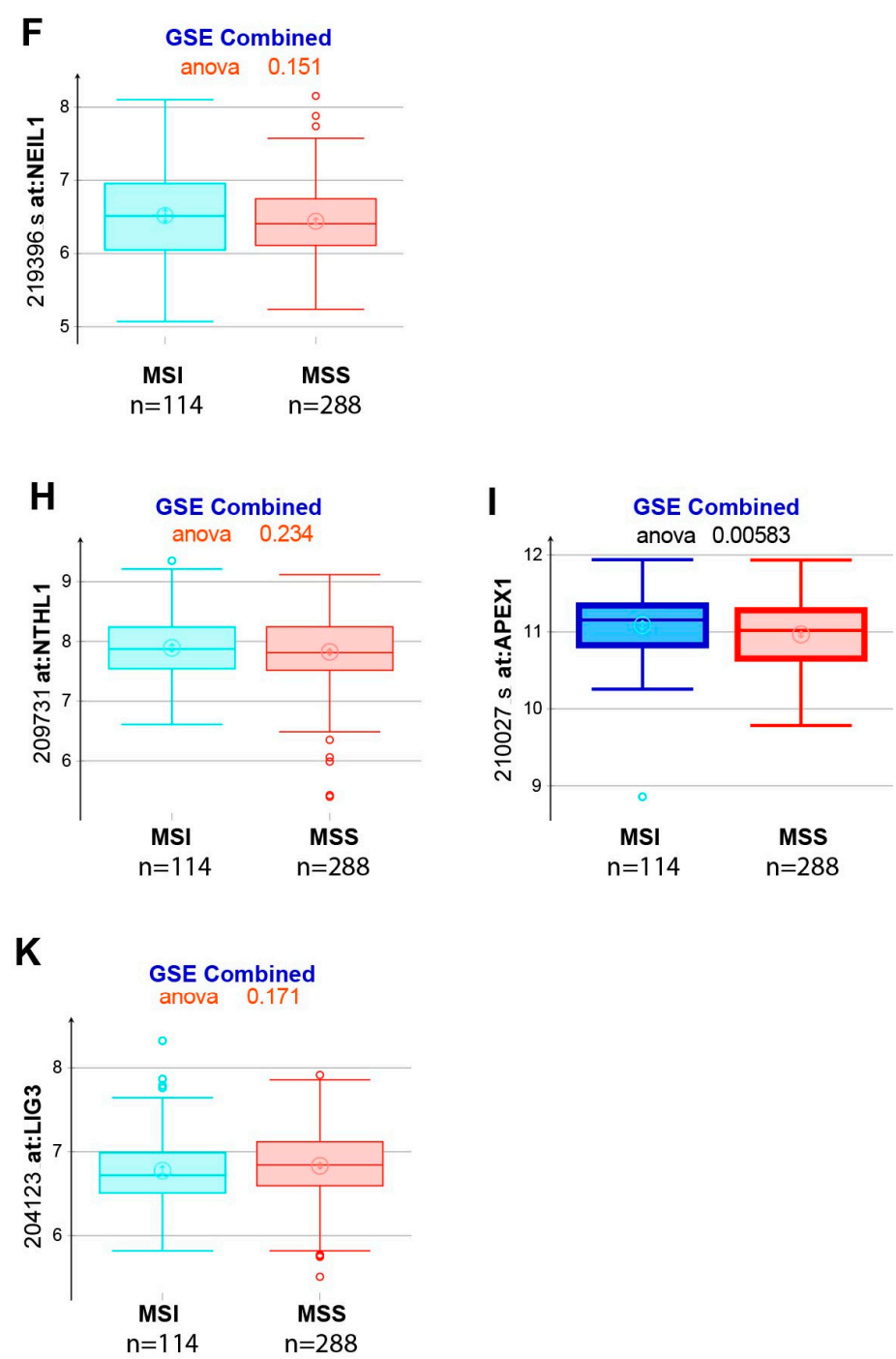

Figure 7. Analysis of NEIL2 in CRCs patients. The expression of BER proteins was analyzed in microsatellite instability (MSI) and microsatellite stable (MSS) groups from the different publicly available datasets GSE13067, GSE13294, GSE26682, and GSE18088 (A-D) The expression level of NEIL2 was determined in the above datasets. In the 4 combined datasets (GSE13067, GSE13294, GSE26682, and GSE18088), the expression levels of NEIL2 (E) NEIL1 (F), OGG1 (G), NTHL1 (H), APEX1 (I), Polb (J), and LigIII (K) were determined in between MSI and MSS CRCs.

\section{Discussion}

Chronic infection and inflammation can cause DNA damage that can be linked to the development of cancer, including CRC. However, to date, there is no report on how colon cancer-associated bacteria 
such as Fn infection can impact DNA damage and inflammation and how the BER proteins play a critical role in the etiology of colorectal cancer. Using 3D stem cell-based organoid-derived monolayer models from humans and mice, we found that $F n$, but not commensals or other gut pathogens, specifically suppressed the NEIL2-mediated BER pathway. Compared to WT EDMs, NEIL2-KO EDMs showed higher inflammatory cytokines (KC/IL-8) and a higher level of oxidative DNA/RNA damage following Fn infection. Notably, Neil2-KO EDMs showed higher levels of $\mathrm{p}-\gamma \mathrm{H} 2 \mathrm{AX}$ and $\mathrm{p}$-ATM after $F n$ infection, indicating the formation of DSBs. There is no evidence, to date, suggesting any direct role of NEIL2 in double-strand break repair (DSBR). We have reported earlier that NEIL2 is involved in transcription-coupled BER (TC-BER), where it remains associated with RNA polymerase II (RNAP II), transcription factors, and multiple repair proteins in a multi-protein complex $[31,65]$. We thus postulate that NEIL2-deficient cells following Fn infection accumulate DNA adducts, which can block DNA transcription and/or replication, leading to the generation of DSBs.

Of note, NTH1, which has overlapping substrate specificities with NEIL2, was significantly upregulated following $F n$ infection, probably as a compensatory mechanism to mitigate NEIL2 deficiency. Such an overexpression of NTH1 can overwhelm the downstream repair process via an excessive incision of DNA lesions, resulting in the accumulation of BER intermediates. The accumulation of two unprocessed DNA strand breaks in close proximity in two opposing strands can also lead to DSB formation. Indeed, the previous report demonstrated that the overexpression of NTH1 could lead to DSB formation, inducing genome stability, and it does so by inhibiting homologous recombination-mediated DSBR [66]. Hence, a balance of the DNA glycosylases would be important to properly maintain genomic integrity. In the current study, we have focused on NEIL2 for the following reasons: (a) No significant difference was observed in embryonic cells with or without wild-type Nth1 following exposure to hydrogen peroxide [67]. In contrast, middle-to-old-aged Neil2-null mice showed the progressive accumulation of oxidative genomic damage, mostly in the transcribed regions, and furthermore, these mice were highly responsive to inflammatory agents [31]. (b) Among other BERs, only NEIL2 is significantly decreased in the MSS group compared to the MSI group (Figure 7). (c) Our current results showed that the measurement of 8-hydroxy guanosine (Figure 3D), LA-PCR (Figure 3E), and the accumulation of double-strand breaks by $\gamma \mathrm{H} 2 \mathrm{AX}$ staining (Figure $4 \mathrm{~A}, \mathrm{~B}$ ) conclusively showed a higher level of DNA strand-break accumulation in WT cells after Fn infection (with a lower NEIL2 expression level). Moreover, the level of DNA damage is significantly higher in Neil2 KO mice infected EDMs compared to WT EDMs after Fn infection.

Therefore, NEIL2 has an important role in reducing inflammation and DNA damage following infection. A recent study showed that $F n$ promoted oral squamous cell carcinoma (OSCC) by upregulating the expression of $\gamma \mathrm{H} 2 \mathrm{AX}$ and the accumulation of DSBs, leading to accelerating the cell cycle and increasing the cell proliferation capacity [26]. Similarly, H. pylori activated ATM due to the induced host genomic instabilities produced by cag PAI-positive strains through the accumulation of DSBs [68]. DSBs are considered to be the major source of chromosomal instability that can drive cancer development. Hence, exploring the mechanism of DSB formation, and the role of NEIL2 therein, is of great importance in understanding the etiology of CRC. Previous work has shown that the reduced expression of the NEIL2 protein is associated with the progression of several types of cancer, including CRC [37]. Additionally, lower NEIL2 expressions within each stage of the disease led to a lower probability of survival compared to patients with higher NEIL2 expressions [59]. Our results showed that $F n$ infection specifically suppressed NEIL2, which, in turn, increased DNA strand-break accumulation and inflammatory responses, leading to the initiation and progression of CRC. To the best of our knowledge, this is the first report where the DNA repair pathway and, specifically, the role of the DNA glycosylase NEIL2 has been extensively studied in the progression of CRC following Fn infection. Hence, this seminal observation of higher DSBs in the Neil2 KO mice EDMs following infection with Fn might open up a new direction to study how NEIL2 deficiency can trigger DSB formation.

$\mathrm{APC}^{\mathrm{Min} /+}$ mice are an excellent experimental model for studying genetic, epigenetic, environmental, and therapeutic aspects of intestinal neoplasia in humans [69]. The oral feeding of $F n$ to APC Min/+ 
mice resulted in accelerated small intestinal and colonic tumorigenesis, the infiltration of specific myeloid-derived immune cell types into tumors, and an NF- $\mathrm{kB}$ proinflammatory gene signature similar to humans [19]. Other bacterial pathogens have been identified that promote colitis-associated CRC in $\mathrm{APC}^{\mathrm{Min} /+}$ mice, such as Bacteroides fragilis and adherent-invasive Escherichia coli strain NC101 [70,71]. We thus studied the effect of $F n$ infection on BER in the colonic EDMs derived from APC ${ }^{\mathrm{Min} /+}$ mice. We used both polyp and noninvolved (n.i.) regions of $\mathrm{APC}^{\mathrm{Min} /+}$ where $F n$ infection downregulated NEIL2 and increased the inflammatory response and the extent of DNA strand-break accumulation. These observations were consistent with our results in human and murine subjects.

Previously, Tahara et al. reported the presence of $F n$ in cancer and in the adjacent normal regions [20]. The prevalence of high Fn was significantly elevated in CIMP (CPG island methylator phenotype)-positive CRCs compared to CIMP-negative cases. In addition, high Fn was significantly associated with molecular features that are common in CIMP CRCs, such as TP53 wild type, hMLH1 methylation positivity, and MSI [20]. This study showed that a large fraction $F n$ is also present in healthy normal and in MSI CRCs. NEIL2 was not reported in this study, and therefore, we did not correlate the level of NEIL2 in this specific study for Fn load and CRC subtypes. Further studies are required to understand the mechanism and any specific correlation between the level of NEIL2 following $F n$ association with MSI and MSS CRCs.

Furthermore, we investigated the expression of several other BER genes in MSI and MSS CRC cohorts using the publicly available data. Interestingly, only NEIL2 is downregulated in the MSS CRC cohort compared to the MSI cohort, consistent with our experimental observations. MSI occurs when the MMR genes stop functioning at their highest potential, and it is often associated with Lynch syndrome. The direct evidence regarding the link between BER and MMR was shown in MUTYH-associated polyposis (MAP), where MUTYH interacts with MMR gene products [72]. Genetic defects or inherited variations in BER proteins is a predisposing factor for the development of CRC [73,74]. Importantly, one novel missense variant of NEIL2 (C367A) was identified in 94 familial CRC cases but not in the 188 healthy control DNA [75]. The search for other variants, and detailed biochemical characterizations of those variants, are necessary to demonstrate the role of NEIL2 in CRC pathogenesis convincingly. DNA repair capacity via the BER pathway also represents a potential prognostic biomarker, and it is associated with patients' survival and prediction of therapy responses [76]. More detailed mechanistic studies are required to understand the impact of $F n$ infection in CRC progression and the specific downregulation of the BER protein NEIL2 therein. Such studies will be helpful in effective treatment interventions of CRC and the outcome of therapy.

Author Contributions: Conceptualization, I.M.S., A.C., T.K.H., P.G., and S.D.; methodology, I.M.S., A.C., A.A.A.E.-H., A.S. and A.Z.S.; software, D.S.; validation, I.M.S., A.C. and A.A.A.E.-H.; formal analysis, I.M.S., A.C., A.A.A.E.-H., A.S. and A.Z.S.; investigation, T.K.H. and S.D.; resources, W.J.M.H.; data curation. I.M.S., A.C., A.A.A.E.-H., T.K.H., P.G. and S.D.; writing-original draft preparation, I.M.S.; writing-review and editing, I.M.S., A.C., T.K.H. and S.D.; visualization, T.K.H., P.G. and S.D.; supervision, T.K.H., P.G. and S.D.; project administration, T.K.H. and S.D.; and funding acquisition, T.K.H., P.G. and S.D. All authors have read and agreed to the published version of the manuscript.

Funding: This work was supported, in whole or in part, by the National Institute of Health Grants: DK107585, C3 Padre Pedal MCC pilot grant (to S.D.), R01 NS073976 (to T.K.H.), R01HL145477 (to T.K.H.), W81XWH-18-1-0743 (to T.K.H.), R01 AI141630 (to P.G.), R01-GM138385 (to D.S.), and UG3TR002968 (to P.G. and S.D.). WJM Huang is partially funded by the Edward Mallinckrodt, Jr. Foundation and the National Institutes of Health (NIH) (R01 GM124494 to WJM Huang).

Acknowledgments: We are grateful to the HUMANOID CoRE for providing the organoid media and for biobanking and culture, a part of the human organoid.

Conflicts of Interest: All the authors declare that they have no conflicts of interest. 


\section{Abbreviations}

$\begin{array}{ll}\text { EDTA } & \text { Ethylenediaminetetraacetic acid } \\ \text { TGFb } & \text { Transforming Growth Factor b } \\ \text { PVDF } & \text { Polyvinylidene difluoride } \\ \text { NFkB } & \text { Nuclear factor kappa-light-chain enhancer of activated B-cells } \\ \text { HEPES } & \text { 4-(2-hydroxyethyl)-1-piperazineethanesulfonic acid }\end{array}$

\section{References}

1. Siegel, R.L.; Mph, K.D.M.; Jemal, A. Cancer statistics, 2017. CA Cancer J. Clin. 2017, 67, 7-30. [CrossRef]

2. Slattery, M.L. Diet, lifestyle, and colon cancer. Semin. Gastrointest. Dis. 2000, 11, 142-146.

3. Campbell, P.T.; Cotterchio, M.; Dicks, E.; Parfrey, P.; Gallinger, S.; McLaughlin, J.R. Excess body weight and colorectal cancer risk in Canada: Associations in subgroups of clinically defined familial risk of cancer. Cancer Epidemiol. Biomark. Prev. 2007, 16, 1735-1744. [CrossRef] [PubMed]

4. Zisman, A.L.; Nickolov, A.; Brand, R.E.; Gorchow, A.; Roy, H.K. Associations between the age at diagnosis and location of colorectal cancer and the use of alcohol and tobacco. Arch. Intern. Med. 2006, 166, 629-634. [CrossRef]

5. Botteri, E.; Iodice, S.; Raimondi, S.; Maisonneuve, P.; Lowenfels, A.B. Cigarette smoking and adenomatous polyps: A Meta-analysis. Gastroenterology 2008, 134, 388-395. [CrossRef] [PubMed]

6. Willett, W.C. Diet and cancer: An evolving picture. JAMA 2005, 293, 233-234. [CrossRef] [PubMed]

7. Haggar, F.; Boushey, R.P. Colorectal cancer epidemiology: Incidence, mortality, survival, and risk factors. Clin. Colon Rectal Surg. 2009, 22, 191-197. [CrossRef] [PubMed]

8. Khare, S.; Verma, M. Epigenetics of colon cancer. Adv. Struct. Saf. Stud. 2012, 863, 177-185. [CrossRef]

9. Bellizzi, A.M.; Frankel, W.L. Colorectal cancer due to deficiency in DNA mismatch repair function. Adv. Anat. Pathol. 2009, 16, 405-417. [CrossRef] [PubMed]

10. Richman, S.D. Deficient mismatch repair: Read all about it (Review). Int. J. Oncol. 2015, 47, 1189-1202. [CrossRef] [PubMed]

11. Peltomaki, P. Deficient DNA mismatch repair: A common etiologic factor for colon cancer. Hum. Mol. Genet. 2001, 10, 735-740. [CrossRef] [PubMed]

12. French, A.J.; Sargent, D.J.; Burgart, L.J.; Foster, N.R.; Kabat, B.F.; Goldberg, R.; Shepherd, L.; Windschitl, H.E.; Thibodeau, S.N. Prognostic significance of defective mismatch repair and BRAF V600E in patients with colon cancer. Clin. Cancer Res. 2008, 14, 3408-3415. [CrossRef] [PubMed]

13. Guinney, J.; Dienstmann, R.; Wang, X.; De Reyniès, A.; Schlicker, A.; Soneson, C.; Marisa, L.; Roepman, P.; Nyamundanda, G.; Angelino, P.; et al. The consensus molecular subtypes of colorectal cancer. Nat. Med. 2015, 21, 1350-1356. [CrossRef] [PubMed]

14. Holmes, E.; Li, J.V.; Athanasiou, T.; Ashrafian, H.; Nicholson, J.K. Understanding the role of gut microbiome-host metabolic signal disruption in health and disease. Trends Microbiol. 2011, 19, 349-359. [CrossRef] [PubMed]

15. Tsilimigras, M.C.B.; Fodor, A.; Jobin, C. Carcinogenesis and therapeutics: The microbiota perspective. Nat. Microbiol. 2017, 2, 17008. [CrossRef]

16. Marchesi, J.R.; Dutilh, B.E.; Hall, N.; Peters, W.H.M.; Roelofs, R.; Boleij, A.; Tjalsma, H. Towards the Human Colorectal Cancer Microbiome. PLoS ONE 2011, 6, e20447. [CrossRef]

17. Sobhani, I.; Tap, J.; Roudot-Thoraval, F.; Roperch, J.P.; Letulle, S.; Langella, P.; Corthier, G.; Van Nhieu, J.T.; Furet, J.P. Microbial Dysbiosis in Colorectal Cancer (CRC) Patients. PLoS ONE 2011, 6, e16393. [CrossRef]

18. Kostic, A.D.; Gevers, D.; Pedamallu, C.S.; Michaud, M.; Duke, F.; Earl, A.M.; Ojesina, A.I.; Jung, J.; Bass, A.J.; Tabernero, J.; et al. Genomic analysis identifies association of Fusobacterium with colorectal carcinoma. Genome Res. 2011, 22, 292-298. [CrossRef]

19. Kostic, A.D.; Chun, E.; Robertson, L.; Glickman, J.N.; Gallini, C.A.; Michaud, M.; Clancy, T.E.; Chung, D.C.; Lochhead, P.; Hold, G.L.; et al. Fusobacterium nucleatum potentiates intestinal tumorigenesis and modulates the tumor-immune microenvironment. Cell Host Microbe 2013, 14, 207-215. [CrossRef]

20. Tahara, T.; Yamamoto, E.; Suzuki, H.; Maruyama, R.; Chung, W.; Garriga, J.; Jelinek, J.; Yamano, H.-O.; Sugai, T.; An, B.; et al. Fusobacterium in colonic flora and molecular features of colorectal carcinoma. Cancer Res. 2014, 74, 1311-1318. [CrossRef] 
21. Mima, K.; Cao, Y.; Chan, A.T.; Qian, Z.R.; Nowak, J.A.; Masugi, Y.; Shi, Y.; Song, M.; Da Silva, A.; Gu, M.; et al. Fusobacterium nucleatum in Colorectal Carcinoma Tissue According to Tumor Location. Clin. Transl. Gastroenterol. 2016, 7, e200. [CrossRef] [PubMed]

22. Yu, J.; Chen, Y.; Fu, X.; Zhou, X.; Peng, Y.; Shi, L.; Chen, T.; Wu, Y.; And, T.C. InvasiveFusobacterium nucleatummay play a role in the carcinogenesis of proximal colon cancer through the serrated neoplasia pathway. Int. J. Cancer 2016, 139, 1318-1326. [CrossRef] [PubMed]

23. Yu, T.; Guo, F.; Yu, Y.; Sun, T.; Ma, D.; Han, J.; Qian, Y.; Kryczek, I.; Sun, D.; Nagarsheth, N.; et al. Fusobacterium nucleatum Promotes Chemoresistance to Colorectal Cancer by Modulating Autophagy. Cell 2017, 170, 548-563. [CrossRef] [PubMed]

24. Rubinstein, M.R.; Wang, X.; Liu, W.; Hao, Y.; Cai, G.; Han, Y.W. Fusobacterium nucleatum promotes colorectal carcinogenesis by modulating E-cadherin/ $\beta$-catenin signaling via its FadA adhesin. Cell Host Microbe 2013, 14, 195-206. [CrossRef]

25. Rubinstein, M.R.; Baik, J.E.; Lagana, S.M.; Han, R.P.; Raab, W.J.; Sahoo, D.; Dalerba, P.; Wang, T.C.; Han, Y.W. Fusobacterium nucleatum promotes colorectal cancer by inducing $\mathrm{Wnt} / \beta$-catenin modulator Annexin A1. EMBO Rep. 2019, 20, e47638. [CrossRef]

26. Geng, F.; Zhang, Y.; Lu, Z.; Zhang, S.; Pan, Y. Fusobacterium nucleatum Caused DNA Damage and Promoted Cell Proliferation by the Ku70/p53 Pathway in Oral Cancer Cells. DNA Cell Biol. 2019, 39, 144-151. [CrossRef]

27. Kidane, D. Molecular Mechanisms of H. pylori-Induced DNA Double-Strand Breaks. Int. J. Mol. Sci. 2018, 19, 2891. [CrossRef]

28. Chumduri, C.; Gurumurthy, R.K.; Zietlow, R.; Meyer, T.F. Subversion of host genome integrity by bacterial pathogens. Nat. Rev. Mol. Cell Biol. 2016, 17, 659-673. [CrossRef]

29. Hanahan, D.; Weinberg, R.A. Hallmarks of Cancer: The Next Generation. Cell 2011, 144, 646-674. [CrossRef]

30. Krokan, H.E.; Bjørås, M. Base Excision Repair. Cold Spring Harb. Perspect. Biol. 2013, 5, a012583. [CrossRef]

31. Chakraborty, A.; Wakamiya, M.; Venkova-Canova, T.; Pandita, R.K.; Aguilera-Aguirre, L.; Sarker, A.H.; Singh, D.K.; Hosoki, K.; Wood, T.G.; Sharma, G.; et al. Neil2-null Mice Accumulate Oxidized DNA Bases in the Transcriptionally Active Sequences of the Genome and Are Susceptible to Innate Inflammation. J. Biol. Chem. 2015, 290, 24636-24648. [CrossRef] [PubMed]

32. Sahan, A.Z.; Hazra, T.K.; Das, S. The Pivotal Role of DNA Repair in Infection Mediated-Inflammation and Cancer. Front. Microbiol. 2018, 9, 663. [CrossRef] [PubMed]

33. Schärer, O.D.; Jiricny, J. Recent progress in the biology, chemistry and structural biology of DNA glycosylases. BioEssays 2001, 23, 270-281. [CrossRef]

34. Hegde, M.L.; Hazra, T.K.; Mitra, S. Early steps in the DNA base excision/single-strand interruption repair pathway in mammalian cells. Cell Res. 2008, 18, 27-47. [CrossRef] [PubMed]

35. Hazra, T.K.; Das, A.; Das, S.; Choudhury, S.; Kow, Y.W.; Roy, R. Oxidative DNA damage repair in mammalian cells: A new perspective. DNA Repair 2007, 6, 470-480. [CrossRef]

36. Ba, X.; Aguilera-Aguirre, L.; Rashid, Q.T.A.N.; Bacsi, A.; Radák, Z.; Sur, S.; Hosoki, K.; Hegde, M.L.; Brasier, A.R. The Role of 8-Oxoguanine DNA Glycosylase-1 in Inflammation. Int. J. Mol. Sci. 2014, 15, 16975-16997. [CrossRef]

37. Shinmura, K.; Kato, H.; Kawanishi, Y.; Igarashi, H.; Goto, M.; Tao, H.; Inoue, Y.; Nakamura, S.; Misawa, K.; Mineta, H.; et al. Abnormal Expressions of DNA Glycosylase Genes NEIL1, NEIL2, and NEIL3 Are Associated with Somatic Mutation Loads in Human Cancer. Oxidat. Med. Cell. Longev. 2016, 2016, 1-10. [CrossRef]

38. Dou, H.; Mitra, S.; Hazra, T.K. Repair of Oxidized Bases in DNA Bubble Structures by Human DNA Glycosylases NEIL1 and NEIL2. J. Biol. Chem. 2003, 278, 49679-49684. [CrossRef]

39. Dey, S.; Maiti, A.K.; Hegde, M.L.; Hegde, P.M.; Boldogh, I.; Sarkar, P.S.; Abdel-Rahman, S.; Sarker, A.H.; Hang, B.; Xie, J.; et al. Increased risk of lung cancer associated with a functionally impaired polymorphic variant of the human DNA glycosylase NEIL2. DNA Repair 2012, 11, 570-578. [CrossRef]

40. Sarker, A.H.; Chatterjee, A.; Williams, M.; Lin, S.; Havel, C.; Iii, P.J.; Boldogh, I.; Hazra, T.K.; Talbot, P.; Hang, B. NEIL2 Protects against Oxidative DNA Damage Induced by Sidestream Smoke in Human Cells. PLoS ONE 2014, 9, e90261. [CrossRef]

41. Zhai, X.; Zhao, H.; Liu, Z.; Wang, L.-E.; El-Naggar, A.K.; Sturgis, E.M.; Wei, Q. Functional variants of the NEIL1 and NEIL2 genes and risk and progression of squamous cell carcinoma of the oral cavity and oropharynx. Clin. Cancer Res. 2008, 14, 4345-4352. [CrossRef] [PubMed] 
42. Anurag, M.; Punturi, N.; Hoog, J.; Bainbridge, M.N.; Ellis, M.J.; Haricharan, S. Comprehensive Profiling of DNA Repair Defects in Breast Cancer Identifies a Novel Class of Endocrine Therapy Resistance Drivers. Clin. Cancer Res. 2018, 24, 4887-4899. [CrossRef] [PubMed]

43. Meira, L.; Bugni, J.M.; Green, S.L.; Lee, C.-W.; Pang, B.; Borenshtein, D.; Rickman, B.H.; Rogers, A.B.; Moroski-Erkul, C.A.; McFaline, J.L.; et al. DNA damage induced by chronic inflammation contributes to colon carcinogenesis in mice. J. Clin. Investig. 2008, 118, 2516-2525. [CrossRef] [PubMed]

44. Sayed, I.; Sahan, A.Z.; Venkova, T.; Chakraborty, A.; Mukhopadhyay, D.; Bimczok, D.; Beswick, E.J.; Reyes, V.E.; Pinchuk, I.; Sahoo, D.; et al. Helicobacter pylori infection downregulates the DNA glycosylase NEIL2, resulting in increased genome damage and inflammation in gastric epithelial cells. J. Biol. Chem. 2020, 295, 11082-11098. [CrossRef] [PubMed]

45. Sayed, I.; Suarez, K.; Lim, E.; Singh, S.; Pereira, M.; Ibeawuchi, S.; Katkar, G.; Dunkel, Y.; Mittal, Y.; Chattopadhyay, R.; et al. Host engulfment pathway controls inflammation in inflammatory bowel disease. FEBS J. 2020. [CrossRef]

46. Mahe, M.M.; Sundaram, N.; Watson, C.L.; Shroyer, N.F.; Helmrath, M.A. Establishment of human epithelial enteroids and colonoids from whole tissue and biopsy. J. Vis. Exp. 2015, e52483. [CrossRef]

47. Sato, T.; Vries, R.G.; Snippert, H.J.; Van De Wetering, M.; Barker, N.; Stange, D.E.; Van Es, J.H.; Abo, A.; Kujala, P.; Peters, P.J.; et al. Single Lgr5 stem cells build crypt-villus structures in vitro without a mesenchymal niche. Nature 2009, 459, 262-265. [CrossRef]

48. Miyoshi, H.; Stappenbeck, T.S. In vitro expansion and genetic modification of gastrointestinal stem cells in spheroid culture. Nat. Protoc. 2013, 8, 2471-2482. [CrossRef]

49. Ghosh, P.; Swanson, L.; Sayed, I.; Mittal, Y.; Lim, B.B.; Ibeawuchi, S.-R.; Foretz, M.; Viollet, B.; Sahoo, D.; Das, S. The stress polarity signaling (SPS) pathway serves as a marker and a target in the leaky gut barrier: Implications in aging and cancer. Life Sci. Alliance 2020, 3, e201900481. [CrossRef]

50. Den Hartog, G.; Chattopadhyay, R.; Ablack, A.; Hall, E.H.; Butcher, L.D.; Bhattacharyya, A.; Eckmann, L.; Harris, P.R.; Das, S.; Ernst, P.B.; et al. Regulation of rac1 and reactive oxygen species production in response to infection of gastrointestinal epithelia. PLoS Pathog. 2016, 12, e1005382. [CrossRef]

51. Gào, X.; Holleczek, B.; Cuk, K.; Zhang, Y.; Anusruti, A.; Xuan, Y.; Xu, Y.; Brenner, H.; Schöttker, B. Investigation on potential associations of oxidatively generated DNA/RNA damage with lung, colorectal, breast, prostate and total cancer incidence. Sci. Rep. 2019, 9, 7109. [CrossRef] [PubMed]

52. Rodrigues, D.G.B.; Coelho, D.D.M.; Sitta, Â.; Jacques, C.E.D.; Hauschild, T.; Manfredini, V.; Bakkali, A.; Struys, E.A.; Jakobs, C.; Wajner, M.; et al. Experimental evidence of oxidative stress in patients with 1-2-hydroxyglutaric aciduria and that L-carnitine attenuates in vitro DNA damage caused by d-2-hydroxyglutaric and 1-2-hydroxyglutaric acids. Toxicol. Vitr. 2017, 42, 47-53. [CrossRef]

53. Hsieh, P.; Yamane, K. DNA mismatch repair: Molecular mechanism, cancer, and ageing. Mech. Ageing Dev. 2008, 129, 391-407. [CrossRef] [PubMed]

54. Fukui, K. DNA Mismatch Repair in Eukaryotes and Bacteria. J. Nucleic Acids 2010, 2010, 260512. [CrossRef]

55. Moser, A.R.; Pitot, H.C.; Dove, W.F. A dominant mutation that predisposes to multiple intestinal neoplasia in the mouse. Science 1990, 247, 322-324. [CrossRef]

56. De Smedt, L.; Lemahieu, J.; Palmans, S.; Govaere, O.; Tousseyn, T.; Van Cutsem, E.; Prenen, H.; Tejpar, S.; Spaepen, M.; Matthijs, G.; et al. Microsatellite instable vs. stable colon carcinomas: Analysis of tumour heterogeneity, inflammation and angiogenesis. Br. J. Cancer 2015, 113, 500-509. [CrossRef]

57. Brenner, H.; Kloor, M.; Pox, C.P. Colorectal cancer. Lancet 2014, 383, 1490-1502. [CrossRef]

58. Cancer Genome Atlas Network. Comprehensive molecular characterization of human colon and rectal cancer. Nature 2012, 487, 330-337. [CrossRef]

59. D’Errico, M.; De Rinaldis, E.; Blasi, M.F.; Viti, V.; Falchetti, M.; Calcagnile, A.; Sera, F.; Saieva, C.; Ottini, L.; Palli, D.; et al. Genome-wide expression profile of sporadic gastric cancers with microsatellite instability. Eur. J. Cancer 2009, 45, 461-469. [CrossRef]

60. Jorissen, R.N.; Lipton, L.; Gibbs, P.; Chapman, M.; Desai, J.; Jones, I.T.; Yeatman, T.J.; East, P.; Tomlinson, I.P.; Verspaget, H.W.; et al. DNA Copy-Number Alterations Underlie Gene Expression Differences between Microsatellite Stable and Unstable Colorectal Cancers. Clin. Cancer Res. 2008, 14, 8061-8069. [CrossRef]

61. Gröne, J.; Lenze, D.; Jurinovic, V.; Hummel, M.; Seidel, H.; Leder, G.; Beckmann, G.; Sommer, A.; Grützmann, R.; Pilarsky, C.; et al. Molecular profiles and clinical outcome of stage UICC II colon cancer patients. Int. J. Color. Dis. 2011, 26, 847-858. [CrossRef] [PubMed] 
62. Vilar, E.; Bartnik, C.M.; Stenzel, S.L.; Raskin, L.; Ahn, J.; Moreno, V.; Mukherjee, B.; Iniesta, M.D.; Morgan, M.A.; Rennert, G.; et al. MRE11 deficiency increases sensitivity to poly(ADP-ribose) polymerase inhibition in microsatellite unstable colorectal cancers. Cancer Res. 2011, 71, 2632-2642. [CrossRef]

63. Sanz-Pamplona, R.; Cordero, D.; Berenguer, A.; Lejbkowicz, F.; Rennert, H.; Salazar, R.; Biondo, S.; Sanjuan, X.; Pujana, M.A.; Rozek, L.; et al. Gene expression differences between colon and rectum tumors. Clin. Cancer Res. 2011, 17, 7303-7312. [CrossRef] [PubMed]

64. Schmit, S.L.; Gollub, J.; Shapero, M.H.; Huang, S.-C.; Rennert, H.S.; Finn, A.; Rennert, G.; Gruber, S.B. MicroRNA polymorphisms and risk of colorectal cancer. Cancer Epidemiol. Biomark. Prev. 2014, 24, 65-72. [CrossRef]

65. Banerjee, D.; Mandal, S.M.; Das, A.; Hegde, M.L.; Das, S.; Bhakat, K.K.; Boldogh, I.; Sarkar, P.S.; Mitra, S.; Hazra, T.K. Preferential Repair of Oxidized Base Damage in the Transcribed Genes of Mammalian Cells. J. Biol. Chem. 2011, 286, 6006-6016. [CrossRef]

66. Limpose, K.L.; Trego, K.S.; Li, Z.; Leung, S.W.; Sarker, A.H.; Shah, J.A.; Ramalingam, S.S.; Werner, E.; Dynan, W.S.; Cooper, P.K.; et al. Overexpression of the base excision repair NTHL1 glycosylase causes genomic instability and early cellular hallmarks of cancer. Nucleic Acids Res. 2018, 46, 4515-4532. [CrossRef]

67. Takao, M.; Kanno, S.; Shiromoto, T.; Hasegawa, R.; Ide, H.; Ikeda, S.; Sarker, A.H.; Seki, S.; Xing, J.Z.; Le, X.C.; et al. Novel nuclear and mitochondrial glycosylases revealed by disruption of the mouse Nth1 gene encoding an endonuclease III homolog for repair of thymine glycols. EMBO J. 2002, 21, 3486-3493. [CrossRef]

68. Hanada, K.; Uchida, T.; Tsukamoto, Y.; Watada, M.; Yamaguchi, N.; Yamamoto, K.; Shiota, S.; Moriyama, M.; Graham, D.Y.; Yamaoka, Y. Helicobacter pylori Infection Introduces DNA Double-Strand Breaks in Host Cells. Infect. Immun. 2014, 82, 4182-4189. [CrossRef] [PubMed]

69. Nalbantoglu, I.; Blanc, V.; Davidson, N.O. Characterization of Colorectal Cancer Development in Apc (min/+) Mice. Methods Mol. Biol. 2016, 1422, 309-327. [CrossRef]

70. Wu, S.; Rhee, K.-J.; Albesiano, E.; Rabizadeh, S.; Wu, X.; Yen, H.-R.; Huso, D.L.; Brancati, F.L.; Wick, E.; McAllister, F.; et al. A human colonic commensal promotes colon tumorigenesis via activation of T helper type 17 T cell responses. Nat. Med. 2009, 15, 1016-1022. [CrossRef]

71. Arthur, J.C.; Perez-Chanona, E.; Mühlbauer, M.; Tomkovich, S.; Uronis, J.M.; Fan, T.-J.; Campbell, B.J.; Abujamel, T.; Dogan, B.; Rogers, A.B.; et al. Intestinal Inflammation Targets Cancer-Inducing Activity of the Microbiota. Sciences 2012, 338, 120-123. [CrossRef] [PubMed]

72. Poulsen, M.L.M.; Bisgaard, M.L. MUTYH Associated Polyposis (MAP). Curr. Genom. 2008, 9, $420-435$. [CrossRef] [PubMed]

73. Al-Tassan, N.; Chmiel, N.H.; Maynard, J.; Fleming, N.; Livingston, A.L.; Williams, G.T.; Hodges, A.K.; Davies, D.R.; David, S.S.; Sampson, J.R.; et al. Inherited variants of MYH associated with somatic G:C $\rightarrow$ T:A mutations in colorectal tumors. Nat. Genet. 2002, 30, 227-232. [CrossRef] [PubMed]

74. Farrington, S.M.; Tenesa, A.; Barnetson, R.; Wiltshire, A.; Prendergast, J.G.; Porteous, M.; Campbell, H.; Dunlop, M.G. Germline susceptibility to colorectal cancer due to base-excision repair gene defects. Am. J. Hum. Genet. 2005, 77, 112-119. [CrossRef]

75. Broderick, P.; Bagratuni, T.; Vijayakrishnan, J.; Lubbe, S.; Chandler, I.; Houlston, R.S. Evaluation of NTHL1, NEIL1, NEIL2, MPG, TDG, UNG and SMUG1genes in familial colorectal cancer predisposition. BMC Cancer 2006, 6, 243. [CrossRef]

76. Vodenkova, S.; Jiraskova, K.; Urbanová, M.; Kroupa, M.; Slyskova, J.; Schneiderova, M.; Levy, M.; Buchler, T.; Liska, V.; Vodickova, L.; et al. Base excision repair capacity as a determinant of prognosis and therapy response in colon cancer patients. DNA Repair 2018, 72, 77-85. [CrossRef]

(C) 2020 by the authors. Licensee MDPI, Basel, Switzerland. This article is an open access article distributed under the terms and conditions of the Creative Commons Attribution (CC BY) license (http://creativecommons.org/licenses/by/4.0/). 